\title{
Molecular and cellular designs of insect taste receptor system
}

\author{
Kunio Isono* and Hiromi Morita \\ Graduate School of Information Sciences, Tohoku University, Sendai, Japan
}

\section{Edited by:}

Dieter Wicher, Max Planck Institute for Chemical Ecology, Germany

\section{Reviewed by:}

Satpal Singh, University of New York,

USA

Ulf Bickmeyer, Alfred Wegener

Institute, Germany

\section{${ }^{*}$ Correspondence:}

Kunio Isono, Graduate School of Information Sciences, Tohoku

University, Aramaki, Aoba-ku, Sendai,

Miyagi 980-8579, Japan.

e-mail: iisono@m.tains.tohoku.ac.jp

\begin{abstract}
The insect gustatory receptors (GRs) are members of a large G-protein coupled receptor family distantly related to the insect olfactory receptors. They are phylogenetically different from taste receptors of most other animals. GRs are often coexpressed with other GRs in single receptor neurons. Taste receptors other than GRs are also expressed in some neurons. Recent molecular studies in the fruitfly Drosophila revealed that the insect taste receptor system not only covers a wide ligand spectrum of sugars, bitter substances or salts that are common to mammals but also includes reception of pheromone and somatosensory stimulants. However, the central mechanism to perceive and discriminate taste information is not yet elucidated. Analysis of the primary projection of taste neurons to the brain shows that the projection profiles depend basically on the peripheral locations of the neurons as well as the GRs that they express. These results suggest that both peripheral and central design principles of insect taste perception are different from those of olfactory perception.
\end{abstract}

Keywords: insect, Drosophila, gustatory receptor (GR), taste ligand, taste neuron, taste sensillum, subesophageal ganglion complex (SOG), feeding behavior

\section{INTRODUCTION}

Insect taste organs were first described in the early 20th century as hair-like structures on the distal legs that induce feeding reflex reaction to sugar stimulations in butterflies (Minnich, 1921). The simplicity of insect taste organs innervated by only a few taste neurons was ideal for physiological studies. Single-unit action potentials, sensitivity to taste ligands and other physiological properties were studied intensively during 1950s-1970s using various flies including housefly Musca domestica, blowfly Phormia regina, fleshfly Calliphora erythrocephala and fruitfly Drosophila melanogaster (Dethier, 1976). Morphological or developmental studies were also carried out in flies in 1980s-1990s (Pollack and Balakrishnan, 1997; Singh, 1997).

Molecular studies of insect taste receptors started around the 2000s. Searching the Drosophila genome successfully led to the first discoveries of a large gustatory receptor (GR) gene family and characterization of taste receptor neurons that express divergent GRs (Clyne et al., 2000). The accumulated knowledge in flies from more than half a century of study thus describes various aspects of the insect taste receptor system. However, molecular profiles of fly taste neurons turned out to be much more complex than earlier physiologists predicted. Therefore we are not yet ready to fully understand design principles of taste systems in insects. To gain an insight into how insect taste receptor systems are designed to encode gustatory information, we will focus mainly on the functional aspects of the insect taste receptors and taste receptor neurons. For recent research advances on Drosophila taste receptors and taste perception see other reviews (Amrein and Thorne, 2005; de Bruyne and Warr, 2005; Scott, 2005; Montell, 2009). This review is composed of two parts. Various taste receptor molecules are compared, summarized and discussed in the Section "Insect Taste Receptors". Physiological, morphological, developmental and molecular properties of taste neurons are compared and discussed in the Section "Insect Taste Neurons".

\section{INSECT TASTE RECEPTORS EVOLUTION OF INSECT GUSTATORY RECEPTORS}

Identification of a large family of olfactory G-protein coupled receptor (GPCR) genes by Buck and Axel (1991) provoked searches for taste GPCR genes by molecular biology. A novel family of candidate taste GPCR genes was thus found from the Drosophila genome by a computer algorithm to hit seven-transmembrane domain when the Drosophila genome project was nearly completed (Clyne et al., 2000). They showed that a total of more than 40 GR genes that belong to a novel family and share a signature motif with Drosophila odorant receptor (OR) genes are expressed specifically in taste tissues. Later analysis of the whole Drosophila genome predicted a total of $68 \mathrm{GR}$ genes (Robertson et al., 2003; Table 1). Subsequent molecular and functional studies showed that most of them encode GRs. The genes are given the name "Gr" (gustatory receptor) followed by a chromosomal locus number. When GR genes are tandemly clustered, an alphabet starting from "a" was appended at the end like Gr5a or Gr10b.

Among Drosophila GR genes, 6 are located on the X chromosome while 38 and 24 are found on the second and the third Drosophila chromosome, respectively. Each GR gene encodes a seven-transmembrane receptor protein of about 350-550 amino residues in length. The overall sequences are very divergent with homologies between two randomly chosen GRs as low as $15-25 \%$ on the average, which is significantly lower than those for ORs. However, GRs and ORs share a common amino residue motif in the seventh transmembrane plus $\mathrm{C}$ terminal domain, indicating that they have evolved from an ancestral chemoreceptor family.

Genome analysis suggests that a robust expansion of GR/ OR genes has occurred only in the class Insecta. The nematode Caenorhabditis elegans is an exception since the animal carries a few functional GR genes as will be discussed later. The majority of chemoreceptors in C. elegans, all chemoreceptors in sea urchin (Strongylocentrotus purpuratus) or all gustatory and olfactory receptors in vertebrates do not have GR genes. 
Insects like mosquito, moth, beetle, wasp, bee, aphid and louse are shown to carry both GR and OR genes in the genome (FlyBase, http://flybase.org/). The honey bee Apis mellifera has 163 intact OR genes but only 10 intact GR genes (Robertson and Wanner, 2006). A dipteran insect, the malaria vector mosquito Anopheles gambiae carries 79 and 76 OR and GR genes, respectively (Hill et al., 2002). Numbers of GR genes are therefore similar between the two dipteran insects but their GRs are so distinct that it is often difficult to find common orthologs between the two insects.

Odorant receptor and GR genes of five $D$. melanogaster subgroup species, D. simulans, D. sechellia, D. melanogaster, D. yakuba and D. erecta have been compared recently (McBride and Arguello, 2007). They estimated that the ancestor of the five species carried a total of 64 ancestral ORs and $74 \mathrm{GRs} \sim 12$ million years ago. Interestingly, two ecological specialists, D. sec exclusively depending on Morinda citrifolia as a host plant and D. ere depending on Pandanus candelabrum have lost 14 GRs while three other generalist species have lost only 3 to 6 GRs. GR receptors for $\mathrm{CO}_{2}$ (Gr21a and Gr63a) and for sugars (Gr5a, Gr61a and six Gr64 genes from Gr64a to Gr64f) are more conserved than other GRs including GRs for bitter substances.

Thorne and Amrein (2008) and Kent and Robertson (2009) reported that there are no orthologs of a sugar receptor Gr5a even in some drosophilid species. A BLAST search for Gr5a orthologs and paralogs using the genome assembly data from all available insect species revealed only nine drosophilid species possessing both Gr5a orthologs and paralogs. Other insects including $D$. pseudoobscura, D. persimilis, D. grimshawi, three mosquitoes, a silkworm moth, a red flour beetle, a honeybee, a wasp and a pea aphid have only Gr5a paralogs but no orthologs. A human body louse carries neither paralogs nor orthologs. Gain and loss events of $G r 5 a$ orthologs within 15 dipteran species are estimated and illustrated in Figure 1. Taking into consideration that GR gene family has expanded only in the class Insecta, it seems likely that Gr5a orthologs appeared recently, probably differentiated from $G r 64 f$.

Ueno et al. (2001) showed that a polymorphism of the 218th amino residue $\operatorname{Thr}^{218}\left(\operatorname{Tr} e^{01}\right)$ and $\mathrm{Ala}^{218}\left(\operatorname{Tr}^{+}\right)$in $G r 5 a$ leads to a low and a high trehalose taste sensitivity in D. melanogaster, respectively. $\mathrm{Thr}^{218}$ allele is more frequent than $\mathrm{Ala}^{218}$ allele in wild populations (Inomata et al., 2004). The 218th residue of the Gr5a ortholog in D. simulans and other Drosophila is fixed to $\mathrm{Thr}^{218}$, indicating that $\mathrm{Thr}^{218}$ is ancestral to $\mathrm{Ala}^{218}$, which appeared less than five million years ago only in D. melanogaster. Since $\mathrm{Thr}^{218}$ is almost a null mutation with respect to trehalose sensitivity (Isono et al., 2005), $\mathrm{Ala}^{218}$ must be a gain of function mutation, which seems to be unusual. Other explanations like a second residue polymorphism that compensates the low sugar sensitivity in $\mathrm{Thr}^{218}$ are also possible. Future structure-function studies are necessary to understand the molecular evolution of GRs.

\section{LIGANDS OF INSECT TASTE RECEPTORS}

Attempts to isolate taste receptor proteins biochemically from taste organs of various animals, i.e., bovine, rat and flies, have failed so far although photoreceptor proteins have been successfully isolated from the retina. Taste receptor proteins may be expressed in low amounts in the tissue or the affinity to taste ligands may be too low for affinity-based isolations.

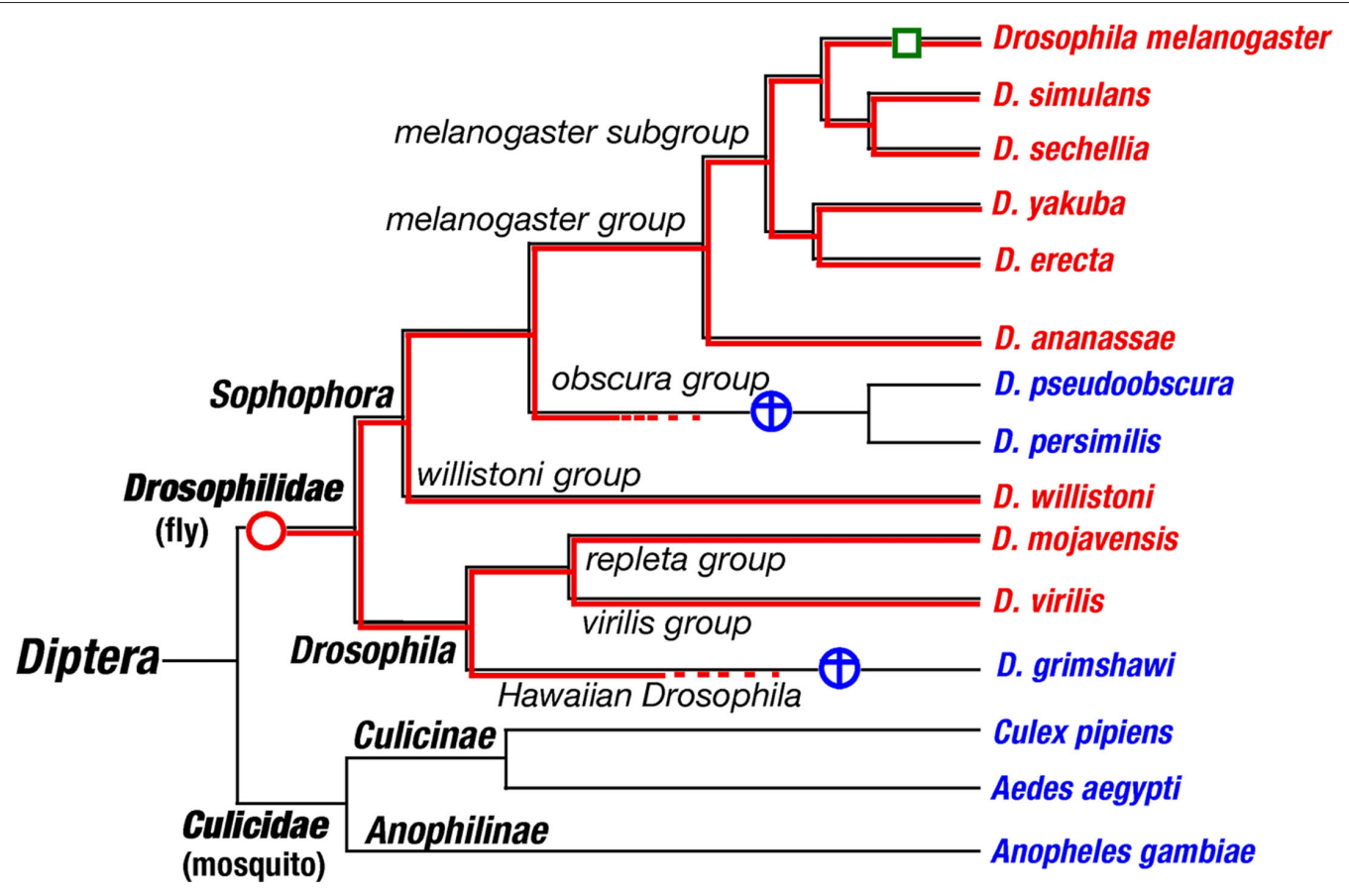

FIGURE 1 | Gain and loss events of Gr5a, a sugar receptor, based on phylogenetic analysis of Gr5a orthologs from 15 dipteran insects in which the whole genome assemblies are available. The phylogenetic tree is modified from BLAST homepage of FlyBase (http://flybase.org/blast/). Species names in red and blue italics illustrate species with or without Gr5a orthologs, respectively. Red and blue circles represent gain and loss events of Gr5a orthologs, respectively. A green box represents a functional mutation from ancestral Thr ${ }^{218}$ to $\mathrm{Ala}^{218}$ that occurred only in Drosophila melanogaster branch. 
Ligand profiles of taste receptors have been analyzed using Drosophila mutants or transformants of a specific GR gene except for the sugar receptor Gr5a using a heterologous expression system (Chyb et al., 2003). As shown in Table 1, the ligands are not yet characterized for many insect GRs. The GR ligands are classified into three groups: sugars, bitter substances and pheromones.

\section{Sugar receptors}

For many insects, including flies, butterflies and bees, the stimulation of taste organs with a sugar solution not only induces neuronal response but also a robust feeding reflex called proboscis extension response (Figure 2) and various appetitive behaviors. Electrophysiological and morphological studies show that the sugar response of a taste sensillum derives from a single sugar-sensitive neuron while other neurons respond to other taste stimulations (Dethier, 1976). Gustatory mutations in Drosophila affecting the neuronal responses were isolated by many laboratories (Isono and Kikuchi, 1974; Falk and Atidia, 1975; Tompkins et al., 1979; Rodrigues and Siddiqi, 1981; Tanimura et al., 1982; Arora et al., 1987). Among them a mutation, Tre (Trehalose-sensitivity, 1-13.6), on the $\mathrm{X}$ chromosome was shown to control sensitivity to a disaccharide trehalose (Tanimura et al., 1982). Among the 68 GRs in Drosophila, Gr5a that locates near the Tre locus became the genomic candidate for Tre and indeed was shown that Tre is identical to Gr5a by disrupting the gene or by genomic rescue experiments (Dahanukar et al., 2001; Ueno et al., 2001; Isono et al., 2005). Tre was also shown to be a single nucleotide polymorphism in Gr5a leading to a substitution of 218 th amino residues $\mathrm{Ala}^{218}\left(=\operatorname{Tr}^{+}\right)$ and $\operatorname{Thr}^{218}\left(=\operatorname{Tr} e^{01}\right)$.

The ligand profile of $G r 5 a$ has been analyzed electrophysiologically and behaviorally using Gr5a mutants (Tanimura et al., 1982; Dahanukar et al., 2001, 2007; Ueno et al., 2001; Chyb et al., 2003; Thorne et al., 2004; Wang et al., 2004; Isono et al., 2005; Jiao et al., 2008). Spontaneous ( $\operatorname{Tr} e^{01}$ ) or induced genomic deletion mutants of $G r 5 a$ are shown to reduce the sensitivity to trehalose, glucose, melezitose, methyl-a-glucoside and some other saccharides.

Another type of sugar receptor was identified by disrupting the six tandemly clustered Gr5a paralogs, Gr64a, Gr64b, Gr64c, Gr64d, Gr64e and Gr64f (Table 1). In contrast to Gr5a, disruptions of the Gr64 cluster lead to a loss of sensitivity to various sugars including sucrose and maltose (Dahanukar et al., 2007; Jiao et al., 2007; Slone et al., 2007). Since disruption of Gr64a alone causes loss of the sugar sensitivity, Gr64a is essential for the sensitivity to sucrose. A more detailed ligand analysis revealed that Gr64a contributes a wide sugar sensitivity not only to sucrose and maltose but also to various di- and trisaccharides or alcohols including turanose, maitotriose, maltitol, palatinose, stachyose, raffinose and leucrose (Dahanukar et al., 2007).

On the other hand, Slone et al. (2007) showed that deletion of all six Gr64 genes leads to a drastic loss of all sugar sensitivity including trehalose and sucrose. Rescue by Gr64a cDNA restored the ligand profile of $G r 64 a$ but did not restore the ligand profile of Gr5a receptor (Jiao et al., 2007). The enigmatic interaction of the two sugar receptors was uncovered by the observation that coexpression of Gr64f receptor is essential for the two complementary profiles of Gr5a and Gr61a receptor functions (Jiao et al., 2008). Thus, Drosophila sugar receptors form heterodimers with
Gr64f receptor as a common co-receptor interacting with Gr5a or with Gr64a receptor. The heterodimeric chemoreceptor model is also suggested for Drosophila caffeine receptors (Lee et al., 2009), Drosophila olfactory $\mathrm{CO}_{2}$ receptors (Suh et al., 2004; Kwon et al., 2007), all olfactory receptors that function with the co-receptor OR83b or its orthologs (Neuhaus et al., 2005), as well as mammalian taste receptors, T1R2/T1R3 sugar reception and T1R2/T1R3 umami reception (Nelson et al., 2001, 2002).

The other five Gr5a-related GR genes, Gr61a, Gr64b, Gr64c, Gr64d and Gr64e have not yet been characterized. Deletions, insertions or suppression by RNAi constructs do not seem to induce significant changes in sugar sensitivity. They may be functional receptors expressed in a limited subset of taste neurons or may simply be nonfunctional receptors as is the case for $T r e^{01}$, the ancestral form of Gr5a.

\section{Bitter receptors}

Properties of bitter taste GRs and bitter taste neurons were studied by Thorne et al. (2004) and Wang et al. (2004). They showed that selective inactivation of taste neurons expressing some GRs by neurotoxins leads to reduction in sensitivity to bitter substances without affecting sugar sensitivity. Thorne et al. (2004) showed that inactivation of Gr66a expressing neurons (hereafter called simply Gr66a neurons) or Gr22e neurons reduces sensitivity to caffeine solutions but not to quinine hydrochloride, denatonium benzoate or berberine solutions at low concentrations in a two-choice behavioral preference assay (Figure 3). However, Wang et al. (2004) showed by a proboscis extension assay (Figure 2) that sensitivity to the four tested bitter substances is simultaneously reduced at wide concentrations in flies where Gr66a neurons are inactivated.

Ligand profile of Gr66a receptor, rather than Gr66a neurons, was later directly analyzed using a Gr66a gene knockout mutant (Moon et al., 2006). The mutant showed reduced sensitivity to wide concentrations of caffeine solutions in the two-choice preference assay (Figure 3) and also in the electrophysiological response of the labellar sensilla (Figure 4). Caffeine is a methylxanthine derivative multiply methylated at three positions (1,3,7-trimethylxanthine). Response to two other derivatives, theophylline (1,3dimethylxanthine) and 1,7-dimethylxanthine was also reduced in the mutant while the response to theobromine (3,7-dimethylxanthine) was normal, suggesting that a strict ligand structure is required for Gr66a receptor.

Gr66a alone is not sufficient to function as a caffeine receptor (Lee et al., 2009). Ablation of the Gr93a gene also reduced the behavioral and electrophysiological caffeine response without affecting the response to many other bitter substances. Since Gr93a mutant flies show exactly the same phenotype as Gr66a mutants, the two GRs may function as heterodimeric co-receptors as was shown for sugar receptors (Jiao et al., 2008). Interestingly, misexpression of both Gr66a and Gr93a cDNAs in Gr5a neurons does not induce response to caffeine, suggesting that the two GRs are not yet sufficient for the caffeine response. Moon et al. (2009) recently showed that Gr33a which is widely expressed in bitter neurons is essential for the neuronal and behavioral response to bitter substances including caffeine, suggesting that caffeine and other bitter receptors are trimeric or multimeric rather than dimeric. Since many GR genes are coexpressed in bitter neurons, 
Table 1 | Gustatory receptor genes in the genome assembly of Drosophila melanogaster with their phylogenetic relations, functions and neuronal expression profiles.

\begin{tabular}{|c|c|c|c|c|c|c|c|}
\hline & Gene name & Group & Ligand & $\begin{array}{l}\text { Tissue } \\
\text { expression* }\end{array}$ & $\begin{array}{l}\text { Coexpressed } \\
\text { with }\end{array}$ & $\begin{array}{l}\text { Not coexpressed } \\
\text { with }\end{array}$ & References \\
\hline 1 & Gr5a & A & Sugars & $L, T p, T$ & $\begin{array}{l}\text { Gr28a, Gr28bC, } \\
\text { Gr61a, Gr64a, } \\
\text { Gr64b, Gr64c, } \\
\text { Gr64d, Gr64e, } \\
\text { Gr64f }\end{array}$ & $\begin{array}{l}\text { Gr22e, Gr32a, Gr33a, } \\
\text { Gr39aD, Gr59f, } \\
\text { Gr63a, Gr66a, Gr98a }\end{array}$ & $\begin{array}{l}\text { Thorne et al. (2004), } \\
\text { Wang et al. (2004), } \\
\text { Fishilevich et al. (2005), } \\
\text { Dahanukar et al. } \\
\text { (2007), Jiao et al. (2007, } \\
\text { 2008), Thorne and } \\
\text { Amrein (2008) }\end{array}$ \\
\hline 2 & Gr61a & A & & $L, T$ & $\begin{array}{l}\text { Gr5a, Gr64a, } \\
\text { Gr64f }\end{array}$ & Gr66a & $\begin{array}{l}\text { Dahanukar et al. } \\
\text { (2007), Jiao et al. } \\
\text { (2007) }\end{array}$ \\
\hline 3 & Gr64a & A & Sugars & $L, P$ & $\begin{array}{l}\text { Gr5a, Gr61a, } \\
\text { Gr64f }\end{array}$ & Gr66a & $\begin{array}{l}\text { Thorne et al. (2004), } \\
\text { Dahanukar et al. } \\
\text { (2007), Jiao et al. (2007, } \\
\text { 2008) }\end{array}$ \\
\hline 4 & Gr64b & A & & L & Gr5a & Gr66a & Jiao et al. (2007) \\
\hline 5 & Gr64c & A & & L & Gr5a & Gr66a & Jiao et al. (2007) \\
\hline 6 & Gr64d & A & & L & Gr5a & Gr66a & Jiao et al. (2007) \\
\hline 7 & Gr64e & A & & $L, P$ & Gr5a & Gr66a & $\begin{array}{l}\text { Thorne et al. (2004), } \\
\text { Jiao et al. (2007) }\end{array}$ \\
\hline 8 & Gr64f & A & Sugars & $L, T$ & $\begin{array}{l}\text { Gr5a, Gr61a, } \\
\text { Gr64a }\end{array}$ & Gr66a & $\begin{array}{l}\text { Dahanukar et al. } \\
\text { (2007), Jiao et al. (2007, } \\
\text { 2008) }\end{array}$ \\
\hline 9 & Gr21a & A & $\mathrm{CO}_{2}$ & $A, L$ & Gr63a & Gr10a & $\begin{array}{l}\text { Clyne et al. (2000), } \\
\text { Scott et al. (2001), Suh } \\
\text { et al. (2004), Couto } \\
\text { et al. (2005), Fishilevich } \\
\text { and Vosshall (2005), } \\
\text { Jones et al. (2007), } \\
\text { Kwon et al. (2007) }\end{array}$ \\
\hline \multirow[t]{2}{*}{10} & Gr63a & $A$ & $\mathrm{CO}_{2}$ & A & Gr21a & Gr5a, Gr10a, Gr66a & $\begin{array}{l}\text { Scott et al. (2001), Jiao } \\
\text { et al. (2007), Jones } \\
\text { et al. (2007), Kwon } \\
\text { et al. (2007) }\end{array}$ \\
\hline & & & & $\mathrm{To}^{* *}$ & Gr21a & & $\begin{array}{l}\text { Fishilevich et al. (2005), } \\
\text { Jones et al. (2007), } \\
\text { Kwon et al. (2007) }\end{array}$ \\
\hline 11 & Gr10a & B & & A & Or10a, Or83b & Gr21a, Gr63a & $\begin{array}{l}\text { Scott et al. (2001), } \\
\text { Fishilevich and Vosshall } \\
\text { (2005), Jones et al. } \\
\text { (2007) }\end{array}$ \\
\hline 12 & Gr59e & B & & & & & \\
\hline
\end{tabular}


Table 1

\begin{tabular}{|c|c|c|c|c|c|c|c|}
\hline & Gene name & Group & Ligand & $\begin{array}{l}\text { Tissue } \\
\text { expression* }\end{array}$ & $\begin{array}{l}\text { Coexpressed } \\
\text { with }\end{array}$ & $\begin{array}{l}\text { Not coexpressed } \\
\text { with }\end{array}$ & References \\
\hline 13 & Gr59f & B & & $L$ & Gr66a & Gr5a & Jiao et al. (2007) \\
\hline 14 & Gr94a & B & & & & & \\
\hline 15 & Gr97a & B & & & & & \\
\hline 17 & Gr77a & C & & & & & \\
\hline 18 & Gr89a & C & & & & & \\
\hline 19 & Gr92a & $\mathrm{D}$ & & & & & \\
\hline 20 & Gr93a & $\mathrm{D}$ & Caffeine & $L, P, T$ & Gr33a, Gr66a & & Lee et al. (2009) \\
\hline 23 & Gr93d & $\mathrm{D}$ & & & & & \\
\hline 24 & Gr22a & $E$ & & $L, W, T$ & & & $\begin{array}{l}\text { Clyne et al. (2000), } \\
\text { Scott et al. (2001) }\end{array}$ \\
\hline \multirow[t]{2}{*}{25} & Gr22b & $E$ & & $L, P, T$ & $\begin{array}{l}\text { Gr22e, Gr28bE, } \\
\text { Gr32a, Gr59b, } \\
\text { Gr66a }\end{array}$ & & $\begin{array}{l}\text { Thorne et al. (2004), } \\
\text { Wang et al. (2004) }\end{array}$ \\
\hline & & & & Po** & Gr66a, Gr68a & & Colomb et al. (2007) \\
\hline 26 & Gr22c & $E$ & & $\mathrm{P}, \mathrm{T}$ & & & $\begin{array}{l}\text { Dunipace et al. (2001), } \\
\text { Wang et al. (2004) }\end{array}$ \\
\hline & & & & To, Po** & Gr66a & & $\begin{array}{l}\text { Fishilevich et al. (2005), } \\
\text { Colomb et al. (2007) }\end{array}$ \\
\hline 29 & Gr22f & $E$ & & $L$ & $\begin{array}{l}\text { Gr22e, Gr59b, } \\
\text { Gr66a }\end{array}$ & & $\begin{array}{l}\text { Dunipace et al. (2001), } \\
\text { Thorne et al. (2004) }\end{array}$ \\
\hline 30 & Gr36a & $E$ & & & & & \\
\hline 31 & Gr36b & $E$ & & & & & \\
\hline 32 & Gr36c & $E$ & & & & & \\
\hline 33 & Gr47a & $E$ & & $L, P$ & Gr66a & $\begin{array}{l}\text { Gr22e, Gr28a, Gr32a, } \\
\text { Gr59b }\end{array}$ & $\begin{array}{l}\text { Clyne et al. (2000), } \\
\text { Scott et al. (2001), } \\
\text { Wang et al. (2004) }\end{array}$ \\
\hline 34 & Gr58a & $E$ & & $L$ & & & Clyne et al. (2000) \\
\hline 35 & Gr58b & $E$ & & $\mathrm{~L}$ & & & Clyne et al. (2000) \\
\hline 36 & Gr58c & $E$ & & $L$ & & & Clyne et al. (2000) \\
\hline 37 & Gr59a & $E$ & & $L$ & & & $\begin{array}{l}\text { Clyne et al. (2000), } \\
\text { Wang et al. (2004) }\end{array}$ \\
\hline
\end{tabular}

(Continued) 
Table 1

\begin{tabular}{|c|c|c|c|c|c|c|c|}
\hline & Gene name & Group & Ligand & $\begin{array}{l}\text { Tissue } \\
\text { expression* }\end{array}$ & $\begin{array}{l}\text { Coexpressed } \\
\text { with }\end{array}$ & $\begin{array}{l}\text { Not coexpressed } \\
\text { with }\end{array}$ & References \\
\hline \multirow[t]{2}{*}{38} & Gr59b & $E$ & & $L$ & $\begin{array}{l}\text { Gr22b, Gr22e, } \\
\text { Gr22f, Gr32a, } \\
\text { Gr66a }\end{array}$ & Gr47a & $\begin{array}{l}\text { Clyne et al. (2000), } \\
\text { Dunipace et al. (2001), } \\
\text { Thorne et al. (2004), } \\
\text { Wang et al. (2004) }\end{array}$ \\
\hline & & & & To & & & Colomb et al. (2007) \\
\hline 40 & Gr59d & $E$ & & $L$ & & & Clyne et al. (2000) \\
\hline 41 & Gr85a & $E$ & & & & & \\
\hline \multirow[t]{2}{*}{42} & Gr32a & $\mathrm{F}$ & Pheromone & $L, P, T$ & $\begin{array}{l}\text { Gr22b, Gr22e, } \\
\text { Gr28a, Gr28bE, } \\
\text { Gr33a, Gr59b, } \\
\text { Gr66a }\end{array}$ & Gr5a, Gr47a & $\begin{array}{l}\text { Clyne et al. (2000), } \\
\text { Scott et al. (2001), } \\
\text { Thorne et al. (2004), } \\
\text { Wang et al. (2004), Jiao } \\
\text { et al. (2007), Miyamoto } \\
\text { and Amrein (2008), Lee } \\
\text { et al. (2009) }\end{array}$ \\
\hline & & & & To** & & Gr66a & $\begin{array}{l}\text { Scott et al. (2001), } \\
\text { Fishilevich et al. (2005), } \\
\text { Colomb et al. (2007) }\end{array}$ \\
\hline 43 & Gr39aA & $\mathrm{F}$ & & $L$ & & & Clyne et al. (2000) \\
\hline 44 & Gr39aB & $\mathrm{F}$ & & L & & & Clyne et al. (2000) \\
\hline 45 & Gr39aC & $\mathrm{F}$ & & $L$ & & & Clyne et al. (2000) \\
\hline 46 & Gr39aD & $\mathrm{F}$ & & $L, W$ & Gr66a & Gr5a & $\begin{array}{l}\text { Clyne et al. (2000), Jiao } \\
\text { et al. (2007) }\end{array}$ \\
\hline 47 & Gr47b & $\mathrm{F}$ & & & & & \\
\hline & & & & $\begin{array}{l}\text { To, Do, Vo, Po, } \\
\text { Vp** }\end{array}$ & & Gr66a & $\begin{array}{l}\text { Scott et al. (2001), } \\
\text { Python and Stocker } \\
\text { (2002), Fishilevich et al. } \\
\text { (2005), Colomb et al. } \\
\text { (2007) }\end{array}$ \\
\hline 51 & Gr8a & G & & & & & \\
\hline 52 & Gr9a & G & & & & & \\
\hline 53 & Gr23aA & G & & $L$ & & & Clyne et al. (2000) \\
\hline 54 & Gr23aB & G & & $\mathrm{L}$ & & & Clyne et al. (2000) \\
\hline 55 & Gr39b & G & & $L$ & & & Clyne et al. (2000) \\
\hline 56 & Gr98a & G & & $\mathrm{L}$ & & Gr5a, Gr66a & $\begin{array}{l}\text { Scott et al. (2001), Jiao } \\
\text { et al. (2007) }\end{array}$ \\
\hline 57 & Gr98b & G & & & & & \\
\hline 58 & Gr98c & G & & & & & \\
\hline 59 & Gr98d & G & & & & & \\
\hline 60 & Gr28a & $\mathrm{H}$ & & $L, P, T$ & $\begin{array}{l}\text { Gr5a, Gr22e, } \\
\text { Gr32a }\end{array}$ & Gr47a & $\begin{array}{l}\text { Wang et al. (2004), } \\
\text { Thorne and Amrein } \\
\text { (2008) }\end{array}$ \\
\hline
\end{tabular}


Table 1

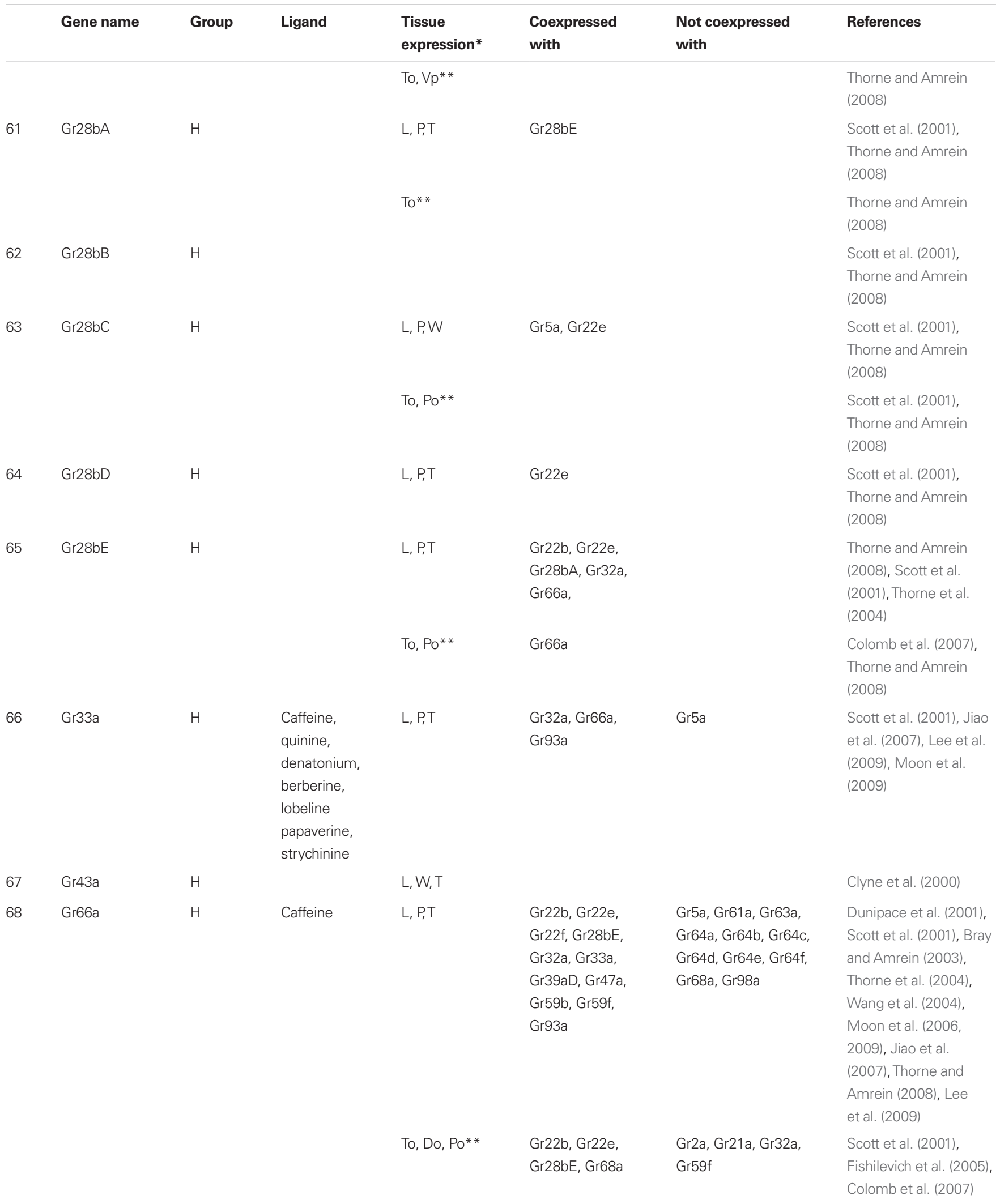

*Expression data in non-chemosensory cells are not indicated. Abbreviations are as follows: for adult tissues: $A$, antenna; $L$, labellum; Tp, taste peg; $P$, pharynx; W, wing; T, tarsal leg segments. For larval tissues: to, terminal organ; Do, dorsal organ; Vo, ventral organ; Po, pharyngeal organ; Vp, ventral pit.

**When GR gene is expressed in both adult and larval tissues, each expression profile is given in the first and the second row, respectively. 

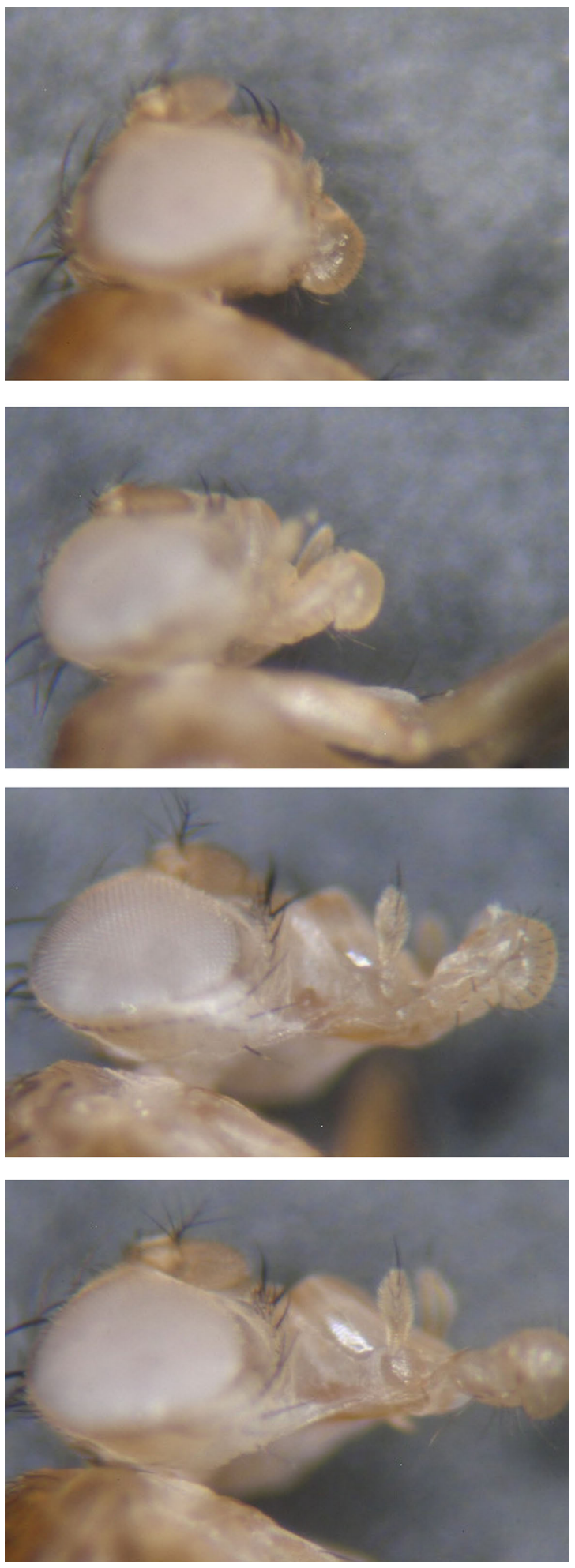

FIGURE 2 | Increasing magnitude of proboscis extension response (from up to down) in Drosophila.

future systematic analysis of GR gene complex may be necessary to understand how each GR contributes to bitter-taste reception in Drosophila.

\section{Pheromone receptors}

Pheromones are volatile and non-volatile chemical substances that are produced for sexual and non-sexual social communications between species members. Two large GPCR families consisting of about $140 \mathrm{~V} 1 \mathrm{Rs}$ and $60 \mathrm{~V} 2 \mathrm{Rs}$, respectively, are expressed in the receptor neurons of the vomeronasal organ in the mouse for pheromone communication (Zufall and Leinders-Zufall, 2007). In insects, however, volatile pheromone-sensing receptors are part of the conventional olfactory receptor system. Sakurai et al. (2004) and Nakagawa et al. (2005) showed that two olfactory pheromone receptors, $B m O R 1$ and $B m O R 3$, are expressed only in the male olfactory neurons of the silk moth Bombyx mori for the detection of female sex pheromones bombykol, (E, Z)-10,12-hexadecadien1-ol, and bombykal, (E, Z)-10,12-hexadecadien-1-al, respectively. Another example in the honeybee is AmOr10, that detects a main component of the queen substance, 9-oxo-2-decenoic acid (Wanner et al., 2007).

In Drosophila a lipid, cis-vaccenyl acetate, has been known to be a male-specific component of the cuticle but is transferred to females upon mating. The lipid acts as an aggregation pheromone for flies of both sexes as well as an inhibitory sex pheromone that suppresses courtship by males (Ejima et al., 2007). Two olfactory receptor genes, Or67d and Or65a, expressed in olfactory neurons of trichoid type olfactory sensilla are shown to encode receptors for cis-vaccenyl acetate. Two other receptors, Or $47 b$ and Or88a, do not respond to cis-vaccenyl acetate but respond to male and female extracts, suggesting that sex pheromones and receptors are complex in Drosophila (van der Goes van Naters and Carlson, 2007).

In addition to volatile sex pheromones, Drosophila also uses gustatory information in male courtship behavior. Gr68a is expressed in male-specific taste neurons of the forelegs and is necessary for normal courtship since inactivation of $\mathrm{Gr} 68 \mathrm{a}$ neurons and RNA interference of Gr68a mRNA lead to a reduction in the courtship performance (Bray and Amrein, 2003). Cuticle non-volatile hydrocarbons like cis, cis-7,11-hepta cosadiene are structurally divergent between sexes and also among Drosophila species and known to promote or suppress courtship in Drosophila males depending on the chemical structures (Jallon, 1984; Ferveur and Jallon, 1996). However, it is not yet clear that Gr68a encodes a hydrocarbon pheromone receptor. Gr68a is broadly expressed in mechanosensory neurons (Ejima and Griffith, 2008). Wild type males show only a poor courtship toward immobilized, silent females in dim light. The performance is greatly improved when they were given a noise arising from fly movements or even artificial white noise. However, the improvement is not observed for transgenic males where Gr68a neurons are inactivated, suggesting that Gr68a receptor and/ or Gr68a neurons contribute to mechanoreceptive rather than chemoreceptive function.

A second candidate pheromone receptor gene, Gr32a, is closely related to Gr68a and was recently shown to be involved in courtship suppression toward males and mated females (Miyamoto and Amrein, 2008). Gr32a may be a long-chain hydrocarbon receptor for inhibitory hydrocarbons like cis-7 tricosene that are shown to inhibit male-male courtship (Ferveur and Jallon, 1996). 

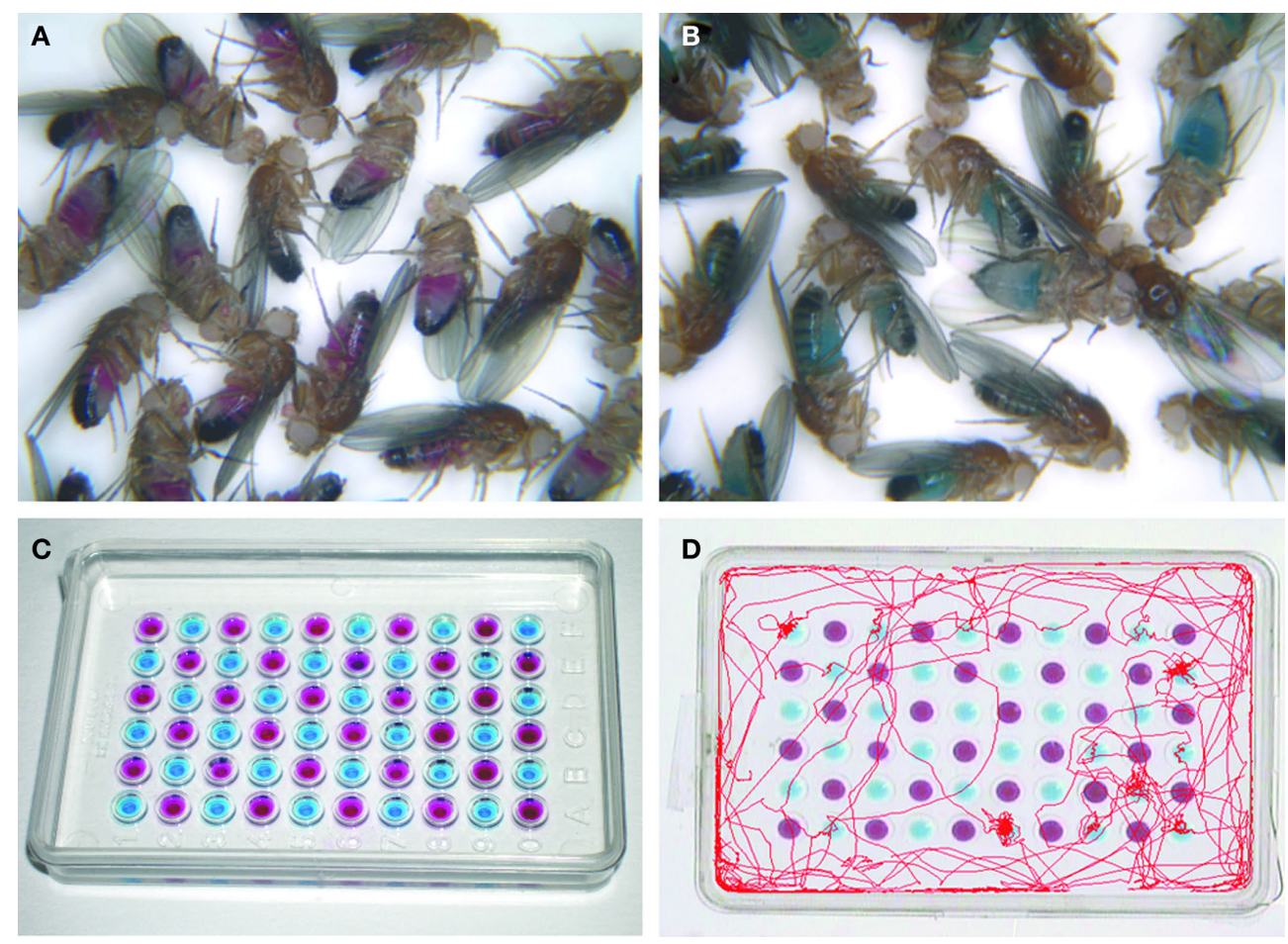

FIGURE 3 |An example of feeding choice test to behaviorally evaluate taste sensitivity and feeding preference in Drosophila. (A,B) Hungry flies after $20 \mathrm{~h}$ of food deprivation ingest a maximum amount of $100 \mathrm{mM}$ sucrose $+1 \%$ agar solutions mixed with red or blue food dyes, respectively, and can be visually inspected after feeding. (C) A microtiter dish containing two different solutions containing the two food dyes to test for the feeding preference. (D) A video

analysis simultaneously monitoring the locomotor traces of three individual flies in the choice of $100 \mathrm{mM}$ sucrose $+1 \%$ agar solution (marked with a blue dye) and a plain $1 \%$ agar solution (marked with a red dye). The traces show that more frequent visits or stays were made on wells containing $100 \mathrm{mM}$ sucrose than on wells containing plain water. The video analysis was provided courtesy of Dr. M. Koganezawa).

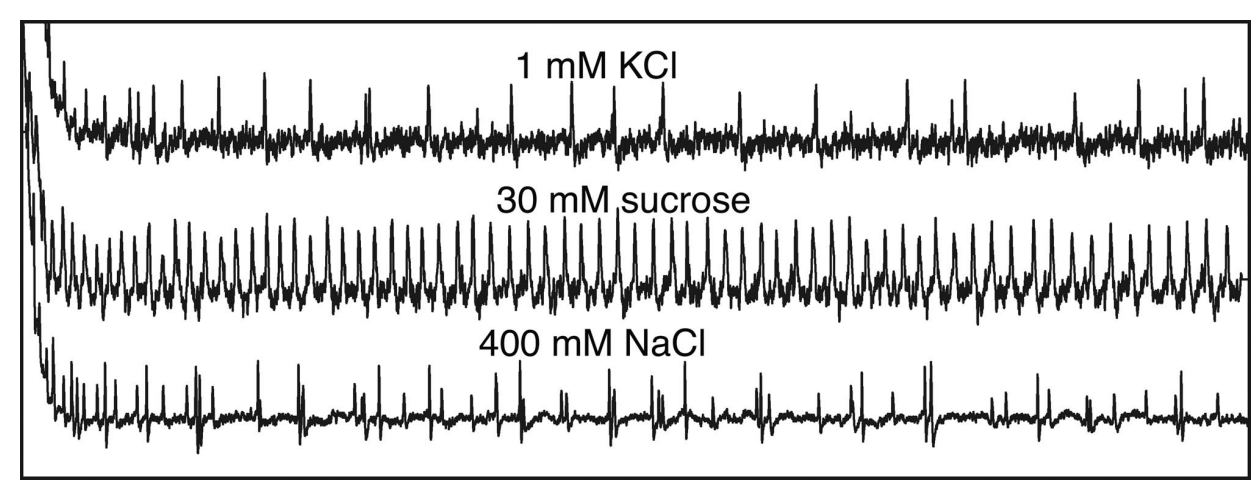

FIGURE 4 | Electrophysiological recordings from a single L-type taste sensillum of the labellum in Drosophila. Different types of neurons are activated by different taste stimulations. See explanations in the text. Recordings provided courtesy of Dr. N. Tanabe.

Suh et al. (2004) identified $\mathrm{CO}_{2}$ as a novel nonsexual olfactory pheromone released by stressed Drosophila flies. They found that the released $\mathrm{CO}_{2}$ induces avoidance in nearby flies. The stress $\mathrm{OR}$ is encoded by Gr21a, an olfactory GR gene in Drosophila. Jones et al. (2007) showed that the $\mathrm{CO}_{2}$ response is also unique in that Gr21a neurons do not coexpress Or83b, an essential cofactor for all other ORs, but instead coexpress Gr63a. Kwon et al. (2007) showed that the coexpression of Gr21a and Gr63a is necessary and sufficient for
$\mathrm{CO}_{2}$ response by ectopic expression of the two GRs in other olfactory neurons. The malaria mosquito A. gambiae, also coexpresses the two orthologs, GPRGR22 and GPRGR24, respectively, in the antennal neurons. Since $\mathrm{CO}_{2}$ is a potent attractant for mosquitoes, the differing behavioral response to $\mathrm{CO}_{2}$ may indicate that the peripheral design of chemoreceptors is more conserved than the central design which is flexible and species-specific in the evolution of the whole insect chemosensory system. 


\section{Receptors tuned to non-gustatory stimuli}

Phylogenetic analysis suggested that insect OR family arose from an expansion of ancestral GR superfamily (Robertson et al., 2003). Therefore it is not surprising that some GRs like Gr10a, Gr21a or Gr63a are expressed and function in olfactory neurons. Some other GRs seem to be expressed even in non-chemosensory neurons as shown for Gr68a in auditory/mechanosensory neurons (Ejima and Griffith, 2008). Thorne and Amrein (2008) showed that six highly conserved GR genes ( $G r 28 a$ and five Gr28b genes, Gr28bA to Gr28bE, or subgroup $\mathrm{H}$ in Table 1) are expressed in non-chemosensory neurons including abdominal multidendritic neurons, putative hygroreceptive neurons of the aristae, neurons in Johnston's organ of the antenna, proprioceptive neurons of the legs or even the larval and adult brain neurons. Gr28bB and Gr28bC are expressed in central neurosecretory cells that release insulin-like peptides (Ikeya et al., 2002), indicating that the two GRs detect internal sugar levels. Coexpression of a sugar receptor Gr5a with Gr28a or Gr28bC also supports that trehalose taste receptor also function as internal sugar detector of the neurosecretory cells. $G r 28 b B$ is also expressed in nonneural cells like enocytes in adults and larvae that detects nutrient levels to regulate metabolism. The expression profiles suggest that Gr28 receptors are multimodal somatosensory receptors tuned to proprioception, nociception, thermoreception or internal chemoreception. Therefore they may be comparable to mammalian TRP family members (Minke and Parnas, 2006; Ramsey et al., 2006) or divergent, MAS-related GPCRs expressed in the nociceptive neurons of the dorsal root ganglion (Dong et al., 2001).

A photosensitive insect GR homolog, lite-1, was recently identified as one of the three insect GR-related genes in the nematode C. elegans (Edwards et al., 2008). Mutations in lite-1 disrupt lightinduced locomotor activity. Interestingly, lite-1 shows homology to Drosophila Gr28b gene with the highest homology in their C termini (26\% identical over a 68 amino residue length) as are generally the case among GRs in flies. Though no functional studies have yet been carried out for Gr28b receptors in flies, it is possible that some Gr28 receptors in flies encode extraocular, non-visual photoreceptor molecules.

\section{Gustatory TRP channels}

In addition to GR receptors, other types of receptors are also shown to be expressed in taste neurons and contribute to chemoreception. One is painless, a fly homolog of mammalian TRPA1/ ANKTM1 ion channel protein. painless in flies is involved in the rejection of allyl and benzyl isothiocyanate, the pungent taste and insecticidal component of wasabi (Al-Anzi et al., 2006). Like GR receptors painless is expressed in taste neurons of the labellum, pharynx, legs and wings. A subset of labellar painless neurons also coexpress caffeine receptor Gr66a and, conversely, subset of Gr66a neurons coexpress painless. A similar relation was also obtained between painless neurons and Gr32a or Gr47a bitter neurons of the legs in an agreement with the fact that both bitter substances and isothiocyanate are aversive stimuli and induce food rejection. Interestingly, painless neurons are also involved in the post feeding larval avoidance of food media for pupation (Xu et al., 2008). They showed that peripheral sensory neurons located in the ventral side of the larval body express painless and respond to sugar stimulations and that painless mutations or inactivation of painless neurons reduces the food avoidance and also the neuronal response to sugar stimulations. Chemoreceptors involved in the behavioral sugar/ food aversion are not known but it is possible that they are identical to adult sugar receptor GRs. If so, painless neurons should provide a neural model as a developmentally controlled taste evaluation system from acceptance to rejection.

Capsaicin is a hot chili pepper component that activates TRPV1, another type of TRP ion channel in mammals. Capsaicin also induces gustatory response in flies but does not involve painless receptor or painless neurons since it evokes a positive feeding preference in both wild type and painless mutants. Therefore capsaicin receptor in flies, though it has not been identified, may be expressed in food acceptance neurons, rather than in bitter neurons. Other TRP ion channel proteins involve painless subfamily (TRPA) members PYREXIA and dTRPA1 for heat-protection (Tracey et al., 2003; Lee et al., 2005; Xu et al., 2008) and TRPC subfamily members TRP and TRPL for cold protection (Rosenzweig et al., 2008). Future studies may provide evidence that some TRP ion channels are expressed in taste neurons.

Some bitter neurons express a GPCR receptor for an insecticide L-canavaline (2-amnio-4-guanidinooxybutyric acid), a toxin structurally similar to L-arginine, which interferes with normal protein synthesis. The receptor, named DmXR, does not belong to GR but is a family $\mathrm{C}$ member GPCR with a homology to mammalian metabotropic glutamate receptors (mGluRs) and with a long N-terminal extracellular domain. DmXR is expressed in Gr66a neurons of the labellum and the tarsus (Mitri et al., 2009), suggesting that non-GR GPCR receptors are also coexpressed in bitter neurons in addition to multiple bitter GRs.

\section{Uncharacterized taste receptors}

In addition to taste neurons that express known receptor molecules, there are other types of neurons in which no GRs are yet to be identified. For example, electrophysiological analysis showed that there are usually two L1 and L2 neurons in a single taste hair, both responsive to monovalent cations of salts (Dethier, 1976). No GR receptors have yet been shown to be involved in the salt responses. Instead of GRs, another molecular mechanism has been proposed for the salt response. In some mammals degenerin/epithelial $\mathrm{Na}^{+}$ channels (DEG/ENaC) are known to be suppressed by the inhibitor amiloride. Since amiloride also suppresses taste response to salts in mammals, $\mathrm{DEG} / \mathrm{ENaC} \mathrm{Na}{ }^{+}$channel has been a candidate molecular mechanism that directly triggers receptor potential without GPCR or transduction cascades (Halpern, 1998; Herness and Gilbertson, 1999). DEG/ENaC amiloride-sensitive channels are widely conserved ion channels throughout animals. Liu et al. (2003) showed that mutations or disruptions of two Drosophila DEG/ENaC homologs, Pickpocket11 and Pickpocket19, affect taste sensitivity to salts in larval and adult Drosophila without affecting sugar or olfactory sensitivities.

Another example is the $\mathrm{W}$ neuron that responds to water and low osmolarity solutions found in many types of taste sensilla. Meunier et al. (2009) showed in Drosophila tarsal taste sensilla that W neuron response is pharmacologically inhibited by lanthanum ion (known to inhibit calcium channels) and also by calmodulin antagonists, suggesting that an osmolarity-dependent calcium channel is the osmolarity sensor. 
The reception of carbonated water reported by Fischler et al. (2007) may be the most unexpected. A Gal4 enhancer trap line with an expression profile in the taste peg neurons are defective in neuronal response to, and in behavioral preference for soluble $\mathrm{CO}_{2}$ but are normal in detecting and avoiding gaseous $\mathrm{CO}_{2}$ by olfactory $\mathrm{CO}_{2}$ receptors. Conversely, a mutant in Gr63a, one of the essential olfactory $\mathrm{CO}_{2}$ receptors, is defective in detecting and avoiding $\mathrm{CO}_{2}$ by olfaction but normal in detecting and preferring soluble $\mathrm{CO}_{2}$. Gustatory and olfactory detection of $\mathrm{CO}_{2}$ are therefore independent with respect to the chemoreceptors as well as the central signaling process.

How many species of different taste receptors are present in Drosophila? Insect taste response seems to be divergent, including many GRs, non-GR GPCRs, TRP ion channels and other types of receptor molecules. The total number of GR receptors would be increased considerably if functional taste receptors are composed of dimers or multimers of all the possible combinations of coexpressed GRs. However, the number of taste receptors would be much less if specific combinations of GRs are required as were shown for sugar receptors, bitter receptors or $\mathrm{CO}_{2}$ receptors in Drosophila. Future experiments using heterologous expression systems are necessary to understand how different combinations of GRs and other taste receptors modify, disrupt or confer ligand profiles of taste receptors.

\section{INSECT TASTE NEURONS}

Adult and larval taste neuron expresses a specific subset of GR receptors and other types of taste receptors. Coexpression of taste receptors is sometimes required for receptor function as discussed in the previous section but is also important for taste signaling since it affects taste coding and taste discrimination. Here we will summarize and discuss the molecular aspects of taste neurons viewed from their receptor expression profiles as well as their morphological, developmental or physiological profiles.

\section{STRUCTURE, DEVELOPMENT AND PHYSIOLOGY OF TASTE NEURONS}

In contrast to taste buds, the mammalian taste organs, insect taste organs are usually distributed widely on the external surface of the body including the labella in the proboscis, legs, wings (Figure 5) and even the female ovipositors. They belong to sensilla trichodea and often called "taste hair" or "taste bristle" (Wilczek, 1967; Stocker and Schorderet, 1981; Nayak and Singh, 1983). Taste sensilla are also found on the internal labellum and the pharynx. They belong to sensilla basiconica and are sometimes called "taste papillae". A trichodea-type taste sensillum is usually composed of seven to nine cells including two to four taste neurons, a single mechanosensory neuron and a total of four non-neural cells, a trichogen cell, a tormogen cell, thecogen cell and a glial cell. The trichogen and tormogen cell produce hair shaft and socket cuticle materials, respectively. The thecogen and the glial cell wrap the cell bodies of the neuron cluster and their axons, respectively. A taste neuron sends a single, thin dendrite into the sensilla to the terminal pore opening where physical contact with external fluid takes place (Falk and Atidia, 1975). Each neuron also sends an axon proximally to the central nervous system.

Taste sensilla belong to poly-innervated external sensory organs accommodating multiple bipolar neurons (Kankel et al., 1980). Most bristles that cover the cuticle surface, on the other hand, are
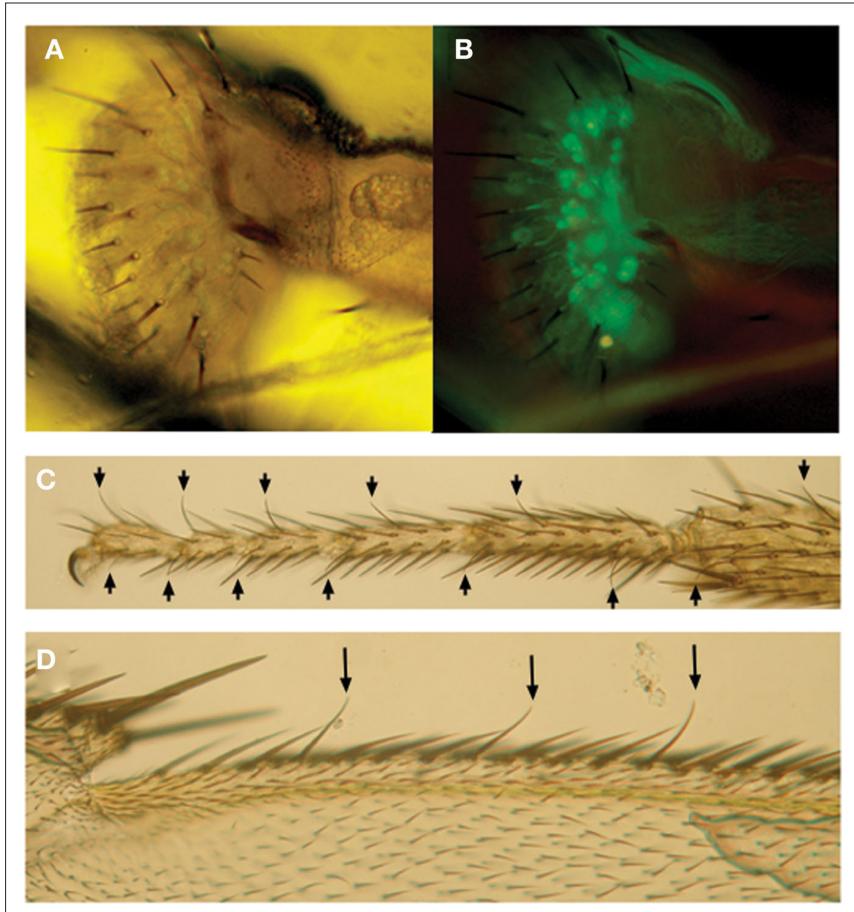

FIGURE 5 | Examples showing taste sensilla and labeled taste neurons in Drosophila. (A,B) Taste sensilla along the peripheral labella of a transformant fly expressing a cytoplasmic GFP marker protein driven by Gr5a promotor-Gal4 (Gr5a-Gal4/Gr5a-Gal4, UAS-2xEGFP/UAS-2xEGFP). Pictures were taken under microscope by transmission light (A) or by fluorescence microscope (B). Arrows in (C) and (D) show other types of taste sensilla along the tarsal segments of the distal legs (C) and wing margins in (D).

mono-innervated bristles containing only a single mechanosensory neuron at the base that detects bristle movement. They both belong to the larger sensory organ category "external sensory bristles" and are developmentally derived from a common ancestral sensory mother cell in the imaginal discs. There are internal sense organs like chordotonal organs of the internal cuticle surface or multiple dendritic neurons in epidermal tissues that are mechanosensory and function as proprioceptive organs. These internal neurons are also derived from the sensory mother cells but by developmentally distinct programs. Sensory organs like olfactory trichoid, basiconic or coeloconic sensilla, or the compound eyes are also external sensory organs but are derived from the eye-antennal imaginal disc by different developmental programs.

While most adult taste organs are newly formed after eclosion, three pharyngeal taste organs - dorsal and ventral cibarial sense organs and labral sense organs - are embryonic and survive throughout the life stages (Gendre et al., 2004).

The identity of a sensory organ is developmentally determined by neurogenic genes and neuron-type selector genes. For example, activities of proneural genes in the achaete-scute gene complex are essential for the formation of sensory organs (García-Bellido and Santamaria, 1978). Once the sensory mother cells are formed, the choice between the external organ or chordotonal organ is regulated by the activity of a neuron-type selector gene cut (Bodmer et al., 1987). The choice between mono-innervated and poly-innervated external sensory organ is regulated by the activity of another 
neuron-type selector gene pox-neuro (poxn) (Dambly-Chaudière et al., 1992). In poxn mutants all external sensory organs become mono-innervated mechanosensory organs (Awasaki and Kimura, 1997). Expression studies of GRs showed that different taste neurons express a distinct GR or a set of GRs. Therefore it is likely that additional, unknown neuron-type selector genes further determine the final taste neuron identities. The final decision seems to be independent from its receptor expression profile since inactivation or ectopic expression of GRs do not affect their projection or other neuronal identities as is true for Drosophila olfactory neurons (Hummel et al., 2003; Komiyama et al., 2004).

The observation that the choice between mechanosensory and taste neurons is regulated by only a single developmental gene poxn also suggests a common ancestral neuron between taste and mechanosensory neurons. In fact, as discussed in the previous section, some GRs are expressed in mechanosensory or proprioceptive non-gustatory neurons (Ejima and Griffith, 2008; Thorne and Amrein, 2008).

There are basically four chemosensory neurons plus one mechanosensory neuron in the external taste organs of adult flies. Electrophysiological studies showed that the four chemosensory neurons are (1) a $S$ neuron that responds to sugar stimuli, (2) a W neuron that responds to water or solutions at low osmolarities, (3) an L1 neuron that responds to salt solutions at lower threshold concentrations and (4) an L2 neuron that responds to salt solutions at higher threshold concentrations (Pollack and Balakrishnan, 1997; see also records in Figure 4). Among them, S neurons are most extensively studied (Dethier and Hanson, 1968; Morita, 1972; Shimada et al., 1974; Fujishiro et al., 1984). S neurons express sugar receptor GRs and positively control feeding by triggering proboscis extension response. L2 neurons also respond to bitter substances (Meunier et al., 2003; Hiroi et al., 2004) and negatively control feeding and suppress the proboscis response. L1 neurons respond to lower concentrations of salt solutions. No GRs are known to be expressed in L1 neurons. It is not known if they are positively or negatively involved in feeding. W neurons respond to pure water, which also induce proboscis extension response when flies are deprived of water. W neurons may also positively control feeding.

Therefore, except for some sensilla that lack W and L1 neurons, all taste sensilla in the labellum had been considered physiologically identical with only four types of taste neurons until the expression and the functional studies of GRs began in this century.

\section{RECEPTOR EXPRESSION AND FUNCTION IN TASTE NEURONS}

Except for a few GRs that are expressed in the olfactory neurons or in the mechanosensory neurons, most GRs are expressed in various taste neurons innervating the adult or larval peripheral taste organs (Figure 5). Expression of GRs is unexpectedly divergent depending on each GR. Tissue expression profile for each GR is summarized in the third column of Table 1. Among 46 GRs so far studied for their expression out of 68 GRs in the fly genome, 40 GRs ( $20 \%)$ are expressed in the labella of the proboscis, the major gustatory organs in adults, supporting the view that most GRs are taste receptors. In addition, a total of 17 GRs are expressed in the tarsal segments of the legs, 16 GRs in the internal taste peg or the pharyngeal taste neurons of the mouth and 7 GRs on the wing margin taste neurons. Since some GRs are expressed widely in the labellum, pharynx and the leg while other GRs are expressed only in one tissue, the overall tissue expression profiles are divergent and complex depending on each GR. In addition some GRs are expressed only in single or a limited numbers of taste neurons or sensilla within a given tissue. Despite the divergence in GR expression, however, the expression profiles are conserved between different individuals and the expression profile is dependent exclusively on GR genes themselves, suggesting that they are developmentally regulated.

GRs are also expressed in larval chemosensory organs. Larval GR expression is less complex since the majority of chemoreceptor neurons are localized in the dorsal and terminal organs of the head compartment. Among GR genes expressed in larvae, two genes, Gr21a and Gr63a, are olfactory CO2 receptor genes. All other GRs expressed in larvae are also expressed in adults, especially in the pharyngeal neurons, supporting that pharyngeal taste organs are of larval origin (Gendre et al., 2004). It is also important to note that the expression studies provide the first molecular evidence that different taste neurons express different taste receptors to process different taste information.

Functional studies were also carried out by mutational analysis of GR genes and by inactivation analysis of GR neurons (Dahanukar et al., 2001, 2007; Ueno et al., 2001; Thorne et al., 2004; Wang et al., 2004; Moon et al., 2006; Jiao et al., 2007; Slone et al., 2007; Jiao et al., 2008; Lee et al., 2009). Physiological and behavioral analyses were carried out. Figure 3 shows a frequently used device to evaluate behavioral taste sensitivity and preference in Drosophila.

Combined studies of the expression and functional analysis of GRs showed that considerable numbers of GRs are coexpressed in one of the two groups, one related to sugar response, another to bitter response, respectively. GRs that are expressed in one neuron type are not usually expressed in other neuron types. The coexpression/ non-coexpression relations among GRs are summarized in the sixth and seventh columns of Table 1 . The expression is often compared with caffeine receptor Gr66a in bitter neurons or with trehalose receptor Gr5a in sugar neurons because they are functionally characterized and are expressed widely in various types of taste sensilla.

In the labellar taste neurons a total of 12 GR genes belonging to various GR subgroups are coexpressed in bitter neurons expressing Gr66a. They are Gr22b, Gr22e, Gr22f, Gr28bE, Gr32a, Gr33a, Gr39aD, Gr47a, Gr59b, Gr59f, Gr68a and Gr93a. Even more GRs may be expressed in bitter neurons. Among them Gr33a is unique since it is essential for many bitter response as described in the Section "Insect Taste Receptors". Most other GR genes may be involved for specific sensitivity to bitter substances by encoding a bitter receptor or a monomeric component of a multimeric receptor.

Sugar neurons belong to the other coexpression group, expressing a subset of eight sugar receptor subgroup A GR genes, Gr5a, Gr61a, Gr64a, Gr64b, Gr64c, Gr64d, Gr64e and Gr64f. Among them Gr64f is shown to be essential for sugar receptor function (Jiao et al., 2008). Gr5a and Gr64a are shown to be required for distinct sugar sensitivity, respectively as described in the Section "Insect Taste Receptors".

Coexpression of multiple receptor molecules in single receptor cells is also observed in mammals. Multiple expression of taste receptors seems to be a common strategy in taste system, as was previously discussed (Adler et al., 2000; Dunipace et al., 2001). In flies, however, 
coexpression profiles of GRs are more complex depending on GRs and taste neurons. For examples, Gr59f, Gr22f, Gr59b are coexpressed with $G r 66 a$ in the labellar neurons but are not expressed in other tissues while Gr22c and Gr2a are expressed in the pharynx Gr66a neurons but not expressed in the labellar neurons (Wang et al., 2004).

Some Gr66a-expressing L2 neurons were shown to respond also to the hydrocarbon $Z$-7-tricosene, an inhibitory sex pheromone that is involved in suppressing male homosexual courtship (Lacaille et al., 2007). Bitter substances in fact inhibit male courtship and, vice versa, Z-7-tricosene behaviorally induces bitter taste response. The contribution by Gr66a neurons to courtship, however, seems to be controversial. Gr32a is a candidate inhibitory pheromone receptor gene since males with a mutated or inactivated Gr32a neurons show abnormally high courtship activity toward males or mated females (Miyamoto and Amrein, 2008). Gr32a is coexpressed in the labellar Gr66a- or Gr22e-expressing bitter neurons while the expression of Gr32a and Gr66a in tarsal neurons do not overlap (Table 1). Since disruption of Gr66a neurons do not lead to the high courtship activity toward males or mated females, they argue that tarsal Gr32a neurons, but not the labellar Gr32a/Gr66a neurons are responsible for the mating suppression.

Studies of bitter taste response in the herbivorous caterpillar Manduca sexta support that discrimination of signals from different bitter neurons are possible. In the caterpillar feeding is robustly suppressed by bitter substances as in flies. However, the caterpillar does not show any suppression by a bitter substance when they are previously kept on a medium containing the same or similar bitter substance. The habituation occurs through a central mechanism, rather than a peripheral adaptation mechanism of the bitter neurons (Glendinning et al., 2001). The animal has only four types of taste organs, or eight pairs of taste sensilla in which a single bitter neuron is innervated. Habituation to a bitter ligand does not generalize to a ligand that stimulates different type of bitter neurons. Therefore it is suggested that the discrimination of bitter ligands is based on distinct higher-order neurons and signaling pathways among qualitatively different bitter substances (Glendinning et al., 2002). Since primary projection of bitter neurons are studied in detail in Drosophila as will be discussed in the next section, similar experiments using Drosophila would be useful to analyze whether the discrimination is based on segregation of the primary projections.

Another type of coexpression was reported by Thorne and Amrein (2008). They showed that Gr5a and Gr22e are coexpressed with Gr28a or Gr28b.c in the neurosecretary cells that produce insulin-like peptides. Since $G r 5 a$ is tuned to trehalose, it is possible that Gr5a is not only a taste receptor for trehalose but also an internal detector for the blood sugar trehalose. Similarly, some GRs like Gr22e may be expressed in non-taste neurons and function as internal nutrient detectors. In fact, a polycystic-kidney-disease-like ion channel (PKD2L1), a candidate mammalian sour taste sensor, is also a cerebrospinal fluid sensor in specific neurons surrounding the central canal of the spinal chord to detect decreases in extracellular $\mathrm{pH}$ in the mouse (Huang et al., 2006).

\section{PRIMARY PROJECTIONS OF TASTE NEURONS}

Taste projections in insects have been studied by Golgi staining and dye labeling of taste neurons in adult and larval central nervous systems of flies, bees, butterflies and other insects (Stocker and
Schorderet, 1981; Nayak and Singh, 1983; Shanbhag and Singh, 1989, 1992; Stocker, 1994; Pollack and Balakrishnan, 1997; Mitchell et al., 1999). Gustatory primary centers thus identified were located in the tritocerebral-subesophageal ganglion complex (SOG) or in the thoracic-abdominal ganglion complex of the ventral nerve chord. In flies, chemosensory as well as mechanosensory neurons project to SOG through one of the three major nerve tracts. (1) The pharyngeal taste neurons send their axons through the pharyngeal or accessory pharyngeal nerve tracts and enter anterior SOG from the dorsolateral direction and terminate in anterior and dorsolateral SOG. (2) Labellar and taste peg neurons send their axons through the labial nerve tract and enter medial SOG from the ventrolateral direction. Labeling single labellar neurons show several projection types within SOG. (3) A subset of tarsal taste neurons of the legs directly send their axons through cervical connectives to posterior SOG while other tarsal taste neurons terminate in thoracic-abdominal ganglions. The ascending axons that enter SOG further proceed to anterior and dorsal direction and arborize in the medial or anterior SOG (Rajashekhar and Singh, 1994). Earlier morphological studies supported the view that the projection of taste neurons is organotopic, depending basically on the location of the peripheral taste organs. They also showed that there are several different types of projection within taste neurons sharing similar peripheral locations. However, these observations did not conclusively show that functionally segregated taste neurons are also segregated for their projection.

One of the important contributions by molecular studies was the observation that projections of sugar neurons and bitter neurons are also segregated (Dunipace et al., 2001; Scott et al., 2001; Thorne et al., 2004; Wang et al., 2004; Dahanukar et al., 2007). Based on these studies and our unpublished data, the basic projection profiles of the two types of taste neurons are schematically illustrated in Figure 6. Pharyngeal taste neurons expressing sugar and bitter receptor GRs send their axons through the pharyngeal nerve and/ or the accessory pharyngeal nerve tract and terminate in an anterior and dorsolateral region in SOG, as have been previously described by earlier morphological studies. Tarsal axons of both sugar and bitter taste neurons enter posterior SOG and proceed along similar thin, two-pronged pathways and arborize along the tracts. Labellar bitter neurons and sugar neurons that enter medial SOG also follow the labial nerve projection profile. Therefore, all bitter neurons and sugar neurons follow the organotopic projection rule. However, fine details in the projection between the two types of neurons are different. Bitter neurons from the left and the right side of the labellum arborize bilaterally and converge to form a single cluster in the central region of the medial SOG. Axons of the bitter neurons from the pharyngeal tract and the tarsal taste neurons project to different regions in SOG. The projections are also bilateral. On the contrary, sugar neurons are mostly, if not all, ipsilateral (Thorne et al., 2004; Wang et al., 2004). In addition, the main projection areas of the sugar neurons are spatially segregated from the bitter projections. These observations first provided structural evidence for distinct locations of the synaptic region to higher-order neurons to process different taste qualities.

Therefore taste information seems to be processed according to two basic principles, organotopic and functional. Since taste neurons basically process chemical information, the latter map 


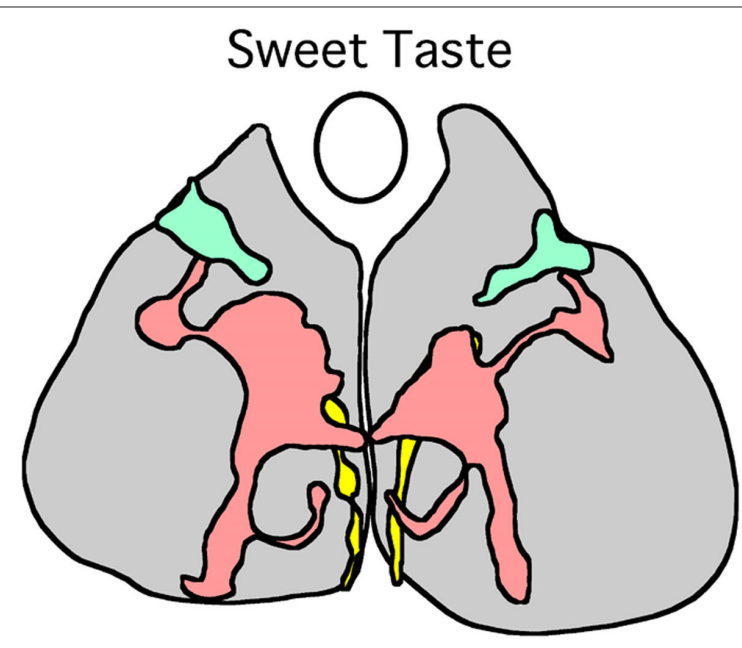

Anterior SOG (Gr61a, Gr64f)

Medial SOG (Gr5a, Gr64f)

Posterior SOG (Gr5a, Gr61a, Gr64f)

FIGURE 6 |A schematic drawing of the primary projection areas in the subesophageal ganglion (SOG) of sugar taste neurons (left) and bitter taste neurons (right). Frontal views of the anterior (blue), medial (pink) and posterior (yellow) projection areas in the SOG are superimposed in the same

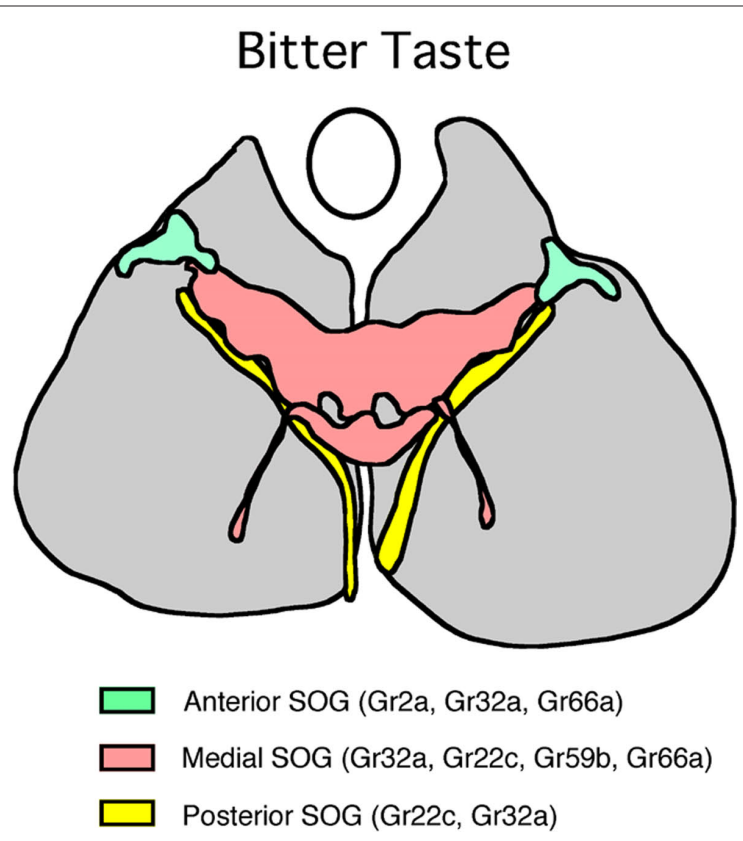

plane. Upward direction is dorsal. An oval represents the location of the esophagus. A subset of sugar receptor genes are indicated for each projection (Dahanukar et al., 2007; Wang et al., 2004). Note distinct projection areas for sugar and bitter neurons. in SOG should reflect distinct pathways of higher-order neurons among different taste qualities. The role of organotopic map in SOG, however, is not so evident. The map may reflect processing of positional information to locate the source of gustatory stimulants as discussed by Wang et al. (2004). Alternatively, the map may reflect distinct output signaling circuits according to different peripheral inputs. For example, leg taste neurons may trigger searching or avoidance behavior while labellar or pharyngeal taste neurons control initiation or rejection of feeding behavior. The organotopic map may also be useful to discriminate between subtle differences in chemical information since neurons from different taste organs are known to express different combinations of GRs. For example, as is shown in Figure 6, labellar sugar neurons express $G r 5 a$ and $G r 64 a$ while tarsal sugar neurons express $G r 5 a$, Gr64a and also Gr61a so that labellar and tarsal sugar neurons may be tuned to different sugar ligands. Similarly, bitter neurons in different taste organs may be tuned to different bitter ligands by expressing different combinations of bitter GRs. The insects may be able to discriminate details among stimulants by integrating gustatory information from different taste organs. Future studies of secondary taste neurons in SOG are necessary to understand how taste information is further processed in the central brain.

\section{REFERENCES}

Adler, E., Hoon, M. A., Mueller, K. L., Chandrashekar, J., Ryba,N.J., and Zuker, C. S. (2000). A novel family of mammalian taste receptors. Cell 100, 693-702.

Al-Anzi, B., Tracey, W. D. Jr., and Benzer, S. (2006). Response of Drosophila to wasabi is mediated by painless, the fly homolog of mammalian TRPA1/ ANKTM1. Curr. Biol. 16, 1034-1040.

Amrein, H., and Thorne, N. (2005). Gustatory perception and behavior in Drosophila melanogaster. Curr. Biol. 15, R673-R684.

\section{CONCLUSIONS}

Insect taste neurons are chemosensory neurons expressing not only taste receptor GRs but also other types of sensory receptors. Since multiple, different subset of GRs are expressed in different types of taste neurons, the overall profiles of receptor expression in the insect taste system are complex in contrast to one receptor - one neuron expression profiles in the olfactory system. By allowing expression of multiple different receptors in single taste neurons insects may be able to expand the ligand spectrum. However, the design would sacrifice performance in discrimination. Future studies on the central mechanism of taste in the insect brain are necessary to understand how insect taste neurons process chemical information and control behavioral outputs.

\section{ACKNOWLEDGMENTS}

We thank Dr. Soh Kohatsu for unpublished GR expression data, Dr. Ryota Adachi for discussions, Dr. Masayuki Koganezawa for providing video analysis in Figure 3 and Dr. Noriko Tanabe for electrophysiological recordings in Figure 4. This work is supported by a grant to K. Isono from the Ministry of Education, Culture, Sports, Science and Technology of Japan.

Arora, K., Rodrigues, V., Joshi, S., Shanbhag, S., and Siddiqi, O. (1987). A gene affecting the specificity of the chemosensory neurons of Drosophila. Nature 330, 62-63.

Awasaki, T., and Kimura, K. (1997). poxneuro is required for development of chemosensory bristles in Drosophila. J. Neurobiol. 32, 707-721.

Bodmer, R., Barbel, S., Sheperd, S., Jack, J. W., Jan, L. Y., and Jan, Y. N. (1987). Transformation of sensory organs by mutations of the cut locus of D. melanogaster. Cell 51, 293-307. 
Bray, S., and Amrein, H. (2003). A putative Drosophila pheromone receptor expressed in male-specific taste neurons is required for efficient courtship. Neuron 39, 1019-1029.

Buck, L., and Axel, R. (1991). A novel multigene family may encode odorant receptors: a molecular basis for odor recognition. Cell 65, 175-187.

Chyb, S., Dahanukar, A., Wickens, A., and Carlson, J. R. (2003). Drosophila Gr5a encodes a taste receptor tuned to trehalose. Proc. Natl. Acad. Sci. U.S.A. 100, 14526-14530.

Clyne, P. J., Warr, C. G., and Carlson, J. R. (2000). Candidate taste receptors in Drosophila. Science 287, 1830-1834.

Colomb, J., Grillenzoni, N., Ramaekers, A., and Stocker, R. F. (2007). Architecture of the primary taste center of Drosophila melanogaster larvae. J. Comp. Neurol. 502, 834-847.

Couto, A., Alenius, M., and Dickson, B. J. (2005). Molecular, anatomical, and functional organization of the Drosophila olfactory system. Curr. Biol. 15, 1535-1547.

Dahanukar, A., Foster, K., van der Goes van Naters, W. M., and Carlson, J. R. (2001). A Gr receptor is required for response to the sugar trehalose in taste neurons of Drosophila. Nat. Neurosci. 4, 1182-1186.

Dahanukar, A., Lei, Y. T., Kwon, J. Y., and Carlson, J. R. (2007). Two Gr genes underlie sugar reception in Drosophila. Neuron 56, 503-516.

Dambly-Chaudière, C., Jamet, E., Burri, M., Bopp, D., Basler, K., Hafen, E., Dumont, N., Spielmann, P., Ghysen, A., and Noll, M. (1992). The paired box gene pox neuro: a determinant of poly-innervated sense organs in Drosophila. Cell 69, 159-172.

De Bruyne, M., and Warr, C. G. (2005), Molecular and cellular organization of insect chemosensory neurons. Bioessays 28, 23-34.

Dethier, V. G. (1976). The Hungry Fly: A Physiological Study of the Behavior Associated with Feeding. Cambridge, MA: Harvard University Press.

Dethier, V. G., and Hanson, F. E. (1968). Electrophysiological responses of the chemoreceptors of the blowfly to sodium salts of fatty acids. Proc. Natl. Acad. Sci. U.S.A. 60, 1296-1303.

Dong, X., Han, S., Zylka, M. J., Simon, M. I., and Anderson, D. J. (2001). A diverse family of GPCRs expressed in specific subsets of nociceptive sensory neurons. Cell 106, 619-632.

Dunipace, L., Meister, S., McNealy, C., and Amrein, H. (2001). Spatially restricted expression of candidate taste receptors in the Drosophila gustatory system. Curr. Biol. 11, 822-835.

Edwards, S. L., Charlie, N. K., Milfort, M. C., Brown, B. S., Gravlin, C.N., Knecht,
J. E., and Miller, K. G. (2008). A novel molecular solution for ultraviolet light detection in Caenorhabditis elegans. PLoS Biol. 6, e198. doi: 10.1371/journal.pbio.0060198.

Ejima, A., and Griffith, L. C. (2008). Courtship initiation is stimulated by acoustic signals in Drosophila melanogaster. PLoS ONE 3, e3246. doi: 10.1371/journal.pone.0003246.

Ejima, A., Smith, B. P. C., Lucas, C., van der Goes van Naters, W., Miller, C. J., Carlson, J. R., Levine, J. D., and Griffith, L. C. (2007). Generalization of courtship learning in Drosophila is mediated by cis-vaccenyl acetate. Curr. Biol. 17, 599-605.

Falk, R., and Atidia, J. (1975). Mutation affecting taste perception in Drosophila melanogaster. Nature 254, 325-326.

Faucher, C., Forstreuter, M., Hilker, M., and de Bruyne, M. (2006). Behavioral responses of Drosophila to biogenic levels of carbon dioxide depend on life-stage, sex and olfactory context. J. Exp. Biol. 209, 2739-2748.

Ferveur, J. F., and Jallon, J. M. (1996). Genetic control of male cuticular hydrocarbons in Drosophila melanogaster. Genet. Res. 67, 211-218.

Fischler, W., Kong, P., Marella, S., and Scott, K. (2007). The detection of carbonation by the Drosophila gustatory system. Natutr 448, 1054-1057.

Fishilevich, E., Domingos, A. I., Asahina, K., Naef, F., Vosshall, L. B., and Louis, M. (2005). Chemotaxis behavior mediated by single larval olfactory neurons in Drosophila. Curr. Biol. 15, 2086-2096.

Fishilevich, E., and Vosshall, L. B. (2005). Genetic and functional subdivision of the Drosophila antennal lobe. Curr. Biol. 15, 1548-1553.

Fujishiro, N., Kijima, H., and Morita, H. (1984). Impulse frequency and action potential amplitude in labellar chemosensory neurons of Drosophila melanogaster. J. Insect Physiol. 30, 317-325.

García-Bellido, A., and Santamaria, P. (1978). Developmental analysis of the achaete-scute system of Drosophila melanogaster. Genetics 88, 469-486.

Gendre, N., Lüer, K., Friche, S., Grillenzoni, N., Ramaekers, A., Technau, G.M., and Stocker, R. F. (2004). Integration of complex larval chemosensory organs into the adult nervous system of Drosophila. Development 131, 83-92.

Glendinning, J. I., Davis, A., and Ramaswamy, S. (2002). Contribution of different taste cells and signaling pathways to the discrimination of "bitter" taste stimuli by an insect. J. Neurosci. 22, 7281-7287.

Glendinning, J. I., Domdom, S., and Long, E. (2001). Selective adaptation to noxious foods by a herbivorous insect. $J$. Exp. Biol. 204, 3355-3367.
Halpern, B. P. (1998). Amiloride and vertebrate gustatory responses to $\mathrm{NaCl}$. Neurosci. Biobehav. Rev. 23, 5-47.

Herness, M. S., and Gilbertson, T. A. (1999). Cellular mechanisms of taste transduction. Annu. Rev. Physiol. 61 , 873-900.

Hill, C. A., Fox, A. N., Pitts, R. J., Kent, L. B., Tan, P. L., Chrystal, M. A., Cravchik, A., Collins, F. H., Robertson, H. M. and Zwiebel, L. J. (2002). G proteincoupled receptors in Anopheles gambiae. Science 298, 176-178.

Hiroi, M., Meunier, N., Marion-Poll, F. and Tanimura, T. (2004). Two antagonistic gustatory receptor neurons responding to sweet-salty and bitter taste in Drosophila. J. Neurobiol. 61, 333-342.

Huang, A. L., Chen, X., Hoon, M. A., Chandrashekar, J., Guo, W., Tränkner, D., Ryba, N. J., and Zuker, C. S. (2006). The cells and logic for mammalian sour taste detection. Nature 442 , 934-938.

Hummel, T., Vasconcelos, M. L., Clemens, J.C., Fishilevich, Y., Vosshall, L. B., and Zipursky, S. L. (2003). Axonal targeting of olfactory receptor neurons in Drosophila is controlled by Dscam. Neuron 37, 221-231.

Ikeya, T., Galic, M., Belawat, P., Nairz, K., and Hafen, E. (2002). Nutrientdependent expression of insulin-like peptides from neuroendocrine cells in the CNS contributes to growth regulation in Drosophila. Curr. Biol. 12, 1293-1300.

Inomata, N., Goto, H., Itoh, M., and Isono, K. (2004). A single-amino-acid change of the gustatory receptor gene, Gr5a, has a major effect on trehalose sensitivity in a natural population of Drosophila melanogaster. Genetics 167 1749-1758.

Isono, K., and Kikuchi, T. (1974). Autosomal recessive mutation in sugar response of Drosophila. Nature 248, 243-244.

Isono, K., Morita, H., Kohatsu, S., Ueno, K., Matsubayashi, H., and Yamamoto, M. T. (2005). Trehalose sensitivity of the gustatory neurons expressing wild-type, mutant and ectopic Gr5a in Drosophila. Chem. Senses 30, i275-i276.

Jallon, J.M. (1984). A few chemical words exchanged by Drosophila during courtship and mating. Behav. Genet. $14,441-478$.

Jiao, Y., Moon, S. J., and Montell, C. (2007) A Drosophila gustatory receptor required for the responses to sucrose, glucose, and maltose identified by mRNA tagging. Proc. Natl. Acad. Sci. U.S.A. 104, 14110-14115.

Jiao, Y., Moon, S. J., Wang, X., Ren, Q., and Montell, C. (2008). Gr64f is required in combination with other gustatory receptors for sugar detection in Drosophila. Curr. Biol. 18, 1797-1801.

Jones, W. D., Cayirlioglu, P., Kadow, I. G., and Vosshall, L. B. (2007). Two chemosensory receptors together mediate carbon dioxide detection in Drosophila. Nature 445, 86-90.

Kankel, D. R., Ferrus, A., Garen, S. H., Harte, P. J., and Lewis, P. E. (1980). "The structure and development of the nervous system," in The Genetics and Biology of Drosophila, Vol. 2d, eds M. Ashburner and T. R. F. Wright (London and New York: Academic Press), 295-368.

Kent, L. B., and Robertson, H. M. (2009) Evolution of the sugar receptors in insects. BMC Evol. Biol. 9, 41. doi: 10.1186/1471-2148-9-41.

Komiyama, T., Carlson, J. R., and Luo, L. (2004). Olfactory receptor neuron axon targeting: intrinsic transcriptional control and hierarchical interactions. Nat. Neurosci. 7, 819-825.

Kwon, J. Y., Dahanukar, A., Weiss, L. A., and Carlson, J. R. (2007). The molecular basis of $\mathrm{CO} 2$ reception in Drosophila.Proc. Natl. Acad. Sci.U.S.A. 104, 3574-3578.

Lacaille, F., Hiroi, M., Twele, R., Inoshita, T., Umemoto, D., Manière, G., MarionPoll, F., Ozaki, M., Francke, W., Cobb, M., Everaerts, C., Tanimura, T., and Ferveur, J. F. (2007). An inhibitory sex pheromone tastes bitter for Drosophila males. PLoS ONE 2, e661. doi: 10.1371/ journal.pone.0000661

Lee, Y., Lee, Y., Lee, J., Bang, S., Hyun, S., Kang, J., Hong, S. T., Bae, E., Kaang, B. K., and Kim, J. (2005). Pyrexia is a new thermal transient receptor potential channel endowing tolerance to high temperatures in Drosophila melanogaster. Nat. Genet. 37, 305-310.

Lee, Y., Moon, S. J., and Montell, C. (2009). Multiple gustatory receptors required for the caffeine response in Drosophila.Proc. Natl. Acad. Sci. U.S.A. 106, 4495-4500.

Liu, L., Leonard, A. S., Motto, D. G., Feller, M.A., Price, M.P., Johnson, W. A., and Welsh, M. J. (2003). Contribution of Drosophila DEG/ENaC genes to salt taste. Neuron 39, 133-146.

McBride, C. S., and Arguello, J. R. (2007). Five Drosophila genomes reveal nonneutral evolution and the signature of host specialization in the chemoreceptor superfamily. Genetics 177 , 1395-1416.

Meunier, N., Marion-Poll, F., and Lucas, P. (2009). Water taste transduction pathway is calcium dependent in Drosophila. Chem. Senses 34, 441-449.

Meunier, N., Marion-Poll, F., Rospars, J. P., and Tanimura, T. (2003). Peripheral 
coding of bitter taste in Drosophila. J. Neurobiol. 56, 139-152.

Minke, B., and Parnas, M. (2006). Insights on TRP channels from in vivo studies in Drosophila. Annu. Rev. Physiol. 68, 649-684.

Minnich, D. E. (1921). An experimental study of the tarsal chemoreceptors of two nymphalid butterflies.J. Exp. Zool. 33, 173-203.

Mitchell, B. K., Itagaki, H., and Rivet, M. P. (1999). Peripheral and central structures involved in insect gustation. Microsc. Res. Tech. 47, 401-415.

Mitri, C., Soustelle, L., Framery, B., Bockaert, J., Parmentier, M. L., and Grau, Y. (2009). Plant insecticide L-canavanine repels Drosophila via the insect orphan GPCR DmX. PLoS Biol.7, e1000147. doi: 10.1371/journal. pbio.1000147.

Miyamoto, T., and Amrein, H. (2008). Suppression of male courtship by a Drosophila pheromone receptor. Nat. Neurosci. 11, 874-876.

Montell, C. (2009). A taste of the Drosophila gustatory receptors. Curr. Opin. Neurobiol. 19, 345-353.

Moon, S. J., Köttgen, M., Jiao, Y., Xu, H., and Montel, C. (2006). A taste receptor required for the caffeine response in vivo. Curr. Biol. 16, 1812-1817.

Moon, S. J., Lee, Y., Jiao, Y., and Montell, C. (2009). A Drosophila gustatory receptor essential for aversive taste and inhibiting male-to-male courtship. Curr. Biol. 19, 1623-1627.

Morita, H. (1972). Primary processes of insect chemoreception. Adv. Biophys. 3, 161-198.

Nakagawa, T., Sakurai, T., Nishioka, T., and Touhara, K. (2005). Insect sexpheromone signals mediated by specific combinations of olfactory receptors. Science 307, 1638-1642.

Nayak, S. Y., and Singh, R. N. (1983). Sensilla on the tarsal segments and mouthparts of adult Drosophila melanogaster meigen (Diptera: Drosophilidae). Int. J. Insect Morphol. Embryol. 12, 273-291.

Nelson, G., Chandrashekar, J., Hoon, M. A., Feng, L., Zhao, G., Ryba, N. J. P., and Zuker, C.S. (2002).An amino-acid taste receptor. Nature 416, 199-202.

Nelson, G., Hoon, M. A., Chandrashekar, J., Zhang, Y., Ryba, N. J. P., and Zuker, C. S. (2001). Mammalian sweet taste receptors. Cell 106, 381-390.

Neuhaus, E. M., Gisselmann, G., Zhang, W., Dooley, R., Störtkuhl, K., and
Hatt, H. (2005). Odorant receptor heterodimerization in the olfactory system of Drosophila melanogaster. Nat. Neurosci. 8, 15-17.

Pollack, G., and Balakrishnan, R. (1997). Taste sensilla of flies: function, central neuronal projections, and development. Microsc. Res. Tech. 39, 532-546.

Python, F., and Stocker, R. F. (2002). Adult-like complexity of the larval antennal lobe of D. melanogaster despite markedly low numbers of odorant receptor neurons. J. Comp. Neurol. $445,374-387$

Rajashekhar, K.P., and Singh, R. N. (1994). Neuroarchitecture of the tritocerebrum of Drosophila melanogaster. J. Comp. Neurol. 349, 633-645.

Ramsey, I. S., Delling, M., and Clapham, D. E. (2006). An introduction to TRP channels. Annu. Rev. Physiol. 68, 619-647.

Robertson, H. M., and Wanner, K. W. (2006). The chemoreceptor superfamily in the honey bee, Apis mellifera: expansion of the odorant, but not gustatory, receptor family. Genome Res. 16, 1395-1403.

Robertson, H. M., Warr, C. G., and Carlson, J. R. (2003). Molecular evolution of the insect chemoreceptor gene superfamily in Drosophila melanogaster. Proc. Natl. Acad. Sci. U.S.A. 100, 14537-14542.

Rodrigues, V., and Siddiqi, O. (1981). A gustatory mutant of Drosophila defective in pyranose receptors. Mol. Gen. Genet. 181, 406-408.

Rosenzweig, M., Kang, K., and Garrity, P. A. (2008). Distinct TRP channels are required for warm and cool avoidance in Drosophila melanogaster. Proc. Natl. Acad. Sci. U.S.A. 105, 14668-14673.

Sakurai, T., Nakagawa, T., Mitsuno, H., Mori, H., Endo, Y., Tanoue, S., Yasukochi, Y., Touhara, K., and Nishioka, T. (2004). Identification and functional characterization of a sex pheromone receptor in the silkmoth Bombyx mori. Proc. Natl. Acad. Sci. U.S.A. 101, 16653-16658.

Scott, K. (2005). Taste recognition: food for thought. Neuron 48, 455-464.

Scott, K., Brady, J. R., Cravchik, A., Morozov, P., Rzhetsky, A., Zuker, C., and Axel, R. (2001). A chemosensory gene family encoding candidate gustatory and olfactory receptors in Drosophila. Cell 104, 661-673.
Shanbhag, S. R., and Singh, R. N. (1989). "Projections and functional implications of labellar neurons from individual sensilla of Drosophila melanogaster," in Neurobiology of Sensory Systems, eds R. N. Singh and N. J. Strausfeld (New York and London: Plenum Press), 427-437.

Shanbhag, S. R., and Singh, R. N. (1992). Functional implications of the projections of neurons from individual labellar sensillum of Drosophila melanogaster as revealed by neuronalmarker horseradish peroxidase. Cell Tissue Res. 267, 273-282.

Shimada, I., Shiraishi, A., Kijima, H., and Morita, H. (1974). Separation of two receptor sites in a single labellar sugar receptor of the flesh-fly by treatment with p-chloromercuribenzoate. $J$. Insect Physiol. 20, 605-621.

Singh, R. N. (1997). Neurobiology of the gustatory systems of Drosophila and some terrestrial insects. Microsc. Res. Tech. 39, 547-563.

Slone, J., Daniels, J., and Amrein, H. (2007). Sugar receptors in Drosophila. Curr. Biol. 17, 1809-1816.

Stocker, R. F. (1994). The organization of the chemosensory system in Drosophila melanogaster: a review. Cell Tissue Res. 275, 3-26.

Stocker, R. F., and Schorderet, M. (1981). Cobalt filling of sensory projections from internal and external mouthparts in Drosophila. Cell Tissue Res. 216, 513-523.

Suh, G. S. B., Wong, A. M., Hergarden, A. C., Wang, J.W., Simon, A. F., Benzer, S., Axel, R., and Anderson, D. J. (2004). A single population of olfactory sensory neurons mediates an innate avoidance behaviour in Drosophila. Nature 431 854-859.

Tanimura, T., Isono, K., Takamura, T., and Shimada, I. (1982). Genetic dimorphism in the taste sensitivity to trehalose in Drosophila melanogaster. J. Comp. Physiol. 147, 433-437.

Thorne, N., and Amrein, H. (2008). Atypical expression of Drosophila gustatory receptor genes in sensory and central neurons. J. Comp. Neurol. $506,548-568$.

Thorne, N., Chromey, C., Bray, S., and Amrein, H. (2004). Taste perception and coding in Drosophila. Curr. Biol. 14, 1065-1079.

Tompkins, L., Cardosa, M. J., White, F. V., and Sanders, T. G. (1979). Isolation and analysis of chemosen- sory behavior mutants in Drosophila melanogaster. Proc. Natl. Acad. Sci. U.S.A. 76, 884-887.

Tracey, W. D. Jr., Wilson, R. I., Laurent, G., and Benzer, S. (2003). Painless, a Drosophila gene essential for nociception. Cell 113, 261-273.

Ueno, K., Ohta, M., Morita, H., Mikuni, Y., Nakajima, S., Yamamoto, K., and Isono, K. (2001). Trehalose sensitivity in Drosophila correlates with mutations in and expression of the gustatory receptor gene Gr5a. Curr. Biol. 11, 1451-1455.

van der Goes van Naters, W., and Carlson, J.R. (2007). Receptors and neurons for fly odors in Drosophila. Curr. Biol. 17, 606-612.

Wang, Z., Singhvi, A., Kong, P., and Scott, K. (2004). Taste representations in the Drosophila brain. Cell 117, 981-991.

Wanner, K. W., Nichols, A. S., Walden, K. K. O., Brockmann, A., Luetje, C. W., and Robertson, H. M. (2007). A honey bee odorant receptor for the queen substance 9-oxo-2-decenoic acid. Proc. Natl. Acad. Sci. U.S.A. 104, 14383-14388.

Wilczek, M. (1967). The distribution and neuroanatomy of the labellar sense organs of the blowfly Phormia regina Meigen. J. Morphol. 122, 175-201.

Xu, J., Sornborger, A. T., Lee, J. K., and Shen, P. (2008). Drosophila TRPA channel modulates sugar-stimulated neural excitation, avoidance and social response. Nat. Neurosci. 11, 676-682.

Zufall, F., and Leinders-Zufall, T. (2007). Mammalian pheromone sensing. Curr. Opini. Neurobiol. 17, 483-489.

Conflict of Interest Statement: This research was conducted in the absence of any commercial or financial relationships that could be construed as a potential conflict of interest.

Received: 02 February 2010; paper pending published: 27 February 2010; accepted: 16 May 2010; published online: 18 June 2010. Citation: Isono K and Morita H (2010) Molecular and cellular designs of insect taste receptor system. Front. Cell. Neurosci. 4:20. doi: 10.3389/fncel.2010.00020

Copyright $\odot 2010$ Isono and Morita. This is an open-access article subject to an exclusive license agreement between the authors and the Frontiers Research Foundation, which permits unrestricted use, distribution, and reproduction in any medium, provided the original authors and source are credited. 